ON THE VARIABILITY OF HEMISPHERIC SCALE ENERGY PARAMETERS

by

J. P. McGuirk, E. R. Reiter and A. M. Barbieri

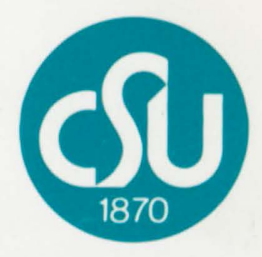

Environmental Research Papers COLORADO STATE UNIVERSITY

Fort Collins. Colorado 
Research on the environment constitutes an important component of the graduate programs pursued by a number of Colorado State University departments. The more noteworthy results of these research efforts are normally published in the conventional professional journals or conference proceedings, but in very much abridged form. ENVIRONMENTAL RESEARCH PAPERS have been established to provide a formal means of disseminating such CSU accomplishments in all significant detail, in order that individuals concerned with related interests at other institutions may review a more comprehensive treatment of the research reported than is customarily available.

Price $-\$ 3.00$ in USA

EDITORIAL BOARD

Dr. Myron L. Corrin, Department of Atmospheric Science

Professor Lewis 0. Grant, Department of Atmospheric Science

Dr. Elmar R. Reiter, (Editor), Department of Atmospheric Science

Dr. David W. Seckler, Department of Economics

Dr. Rodney K. Skogerboe, Department of Chemistry

Subscriptions and correspondence to these papers should be addressed to: Secretary of Environmental Research Papers, Department of Atmospheric Science, Colorado State University, Fort Collins, Colorado 80523. 


\title{
ON THE VARIABILITY OF HEMISPHERIC
} SCALE ENERGY PARAMETERS

\author{
BY \\ J.P. McGuirk, E.R, Reiter \\ \& A.M. BARBIERI
}

Environmental Research Papers

Colorado State University

Fort Collins, Colorado 


\section{TABLE OF CONTENTS}

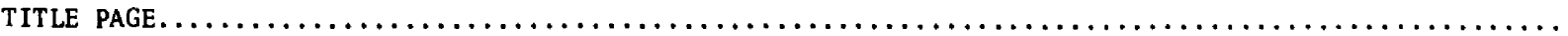

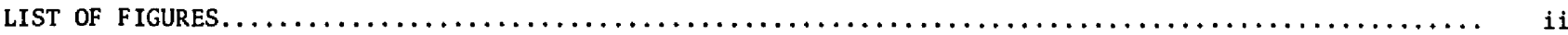

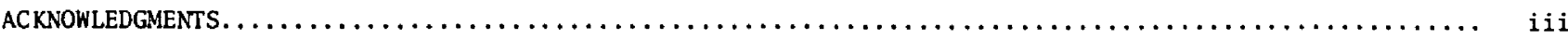

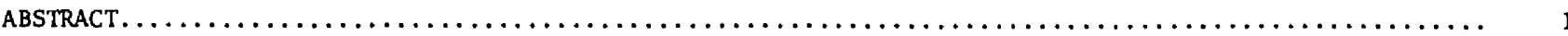

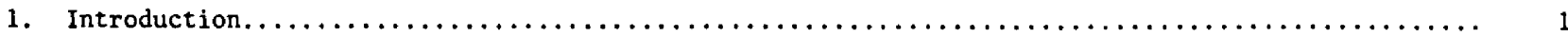

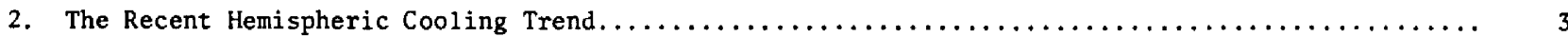

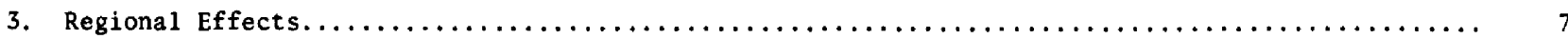

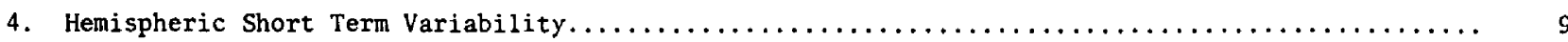

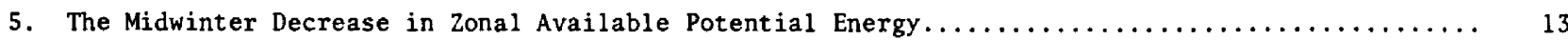

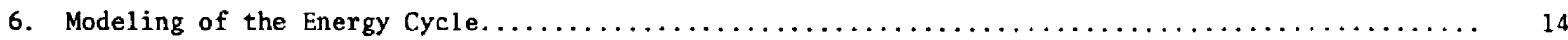

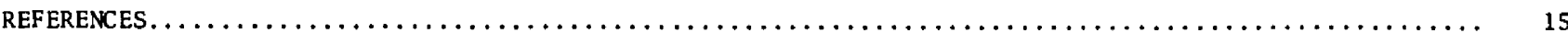

\section{LIST OF FIGURES}

Fig. 1 Spectrum of the kinetic energy of the zonal wind component (after Vinnichenko and Dutton, 1969) units of [ $\left(\mathrm{km}^{2} / \mathrm{hr}^{2}\right)$ day] labelled on right side of diagram, and approximate dollar values of weather-related disasters (partly after Maunder, 1970), labelled on left side

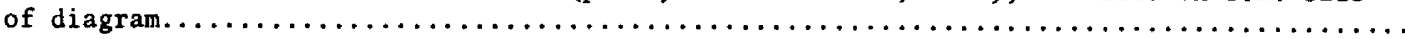

Fig. 2 Mean annual temperature in Iceland over the past millennium. (Data courtesy of $P$. Bergthorsson.) Dashed line shows the rate of decline in the period 1961 to 1971, dotted line indicates the variation of mean temperature in the northern hemisphere plotted to

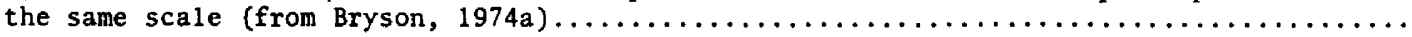

Fig. 3 Duration of drifting ice near the coasts of Iceland in units of weeks per year (after Koch,

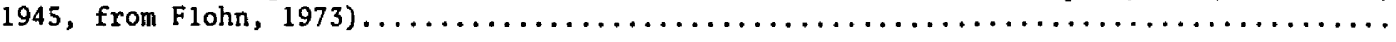

Fig. 4 Correlation between geographic latitude $\left(\phi_{s}\right)$ of the subtropical high-pressure belt and the mean tropospheric (300-700 mb) temperature gradient between equator and pole (after Korff

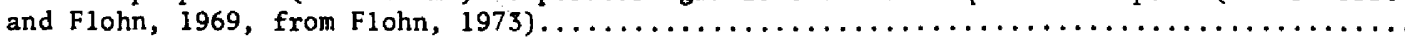

Fig. 5 Trends in the percentage of weather stations in northwestern India reporting less than half of usual annual rainfall in a given year. Overlapping ten-year averages (from Bryson,

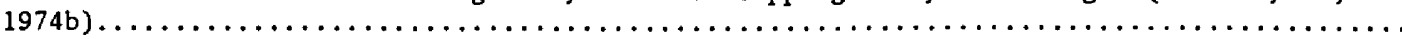

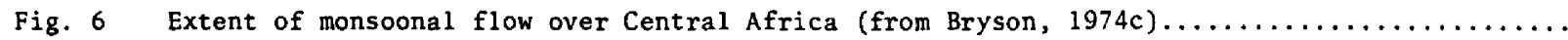

Fig. 7 Lake levels of Lake Chad, Lake Rudolf and Lake Victoria, and run-off of the Nile at Aswan

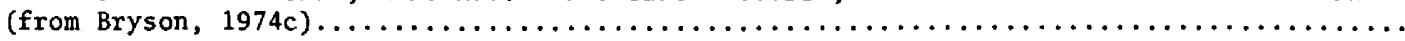

Fig. 8 Departures of the mean temperatures for the decade 1961-1970 from the mean temperatures

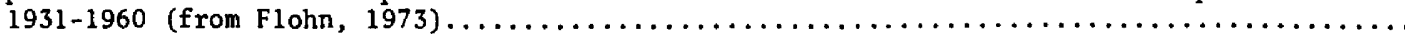

Fig. 9 Annual mean values of the thickness $500 / 100 \mathrm{mb}$ in the latitude regions $\left(65-90^{\circ} \mathrm{N}\right.$, and $50-$ $90^{\circ} \mathrm{N}$ ), expressed as departures from the 20 year normal values (1953-1972) (from Bryson,

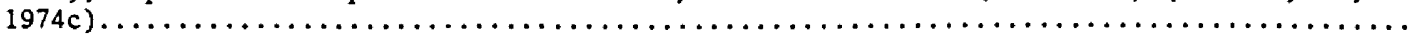

Fig. 10

Mean hemispheric temperatures north of $20^{\circ} \mathrm{N}$ at $500 \mathrm{mb}$.

Fig. 11

Mean January temperatures for various spherical segments of the northern hemisphere.......

Fig. 12

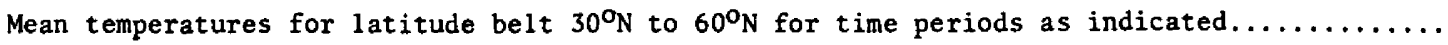

Fig. 13

Mean zonal available potential and kinetic energies (arbitrary units) for January, computed

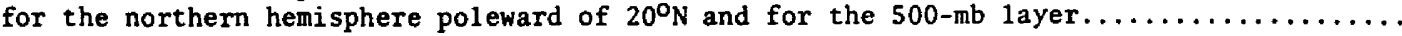

Fig. 14 Mean eddy available potential and kinetic energies (arbitrary units) for January, computed

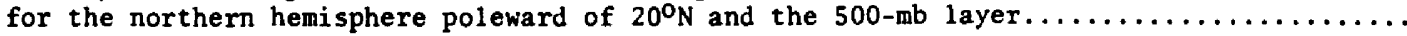

Fig. 15 Area of the cold pool $\left(10^{6} \mathrm{~km}^{2}\right)$ bounded by the $-30^{\circ} \mathrm{C}$ isotherm at 500 mb, and mean area-

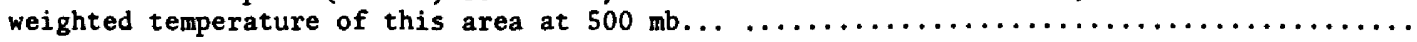

Fig. 16 Daily values for the 1958-1959 cold season of the cold-pool area at $500 \mathrm{mb}$ (i.e., the area bounded by the $-30^{\circ} \mathrm{C}$ isotherm at $500 \mathrm{mb}$ ), the area-weighted temperature of this area at $500 \mathrm{mb}$, and the mean temperature of the spherical segment north of $50^{\circ} \mathrm{N} \ldots \ldots \ldots \ldots \ldots \ldots$

Fig. 17 Mean cold-pool temperature (i.e., mean temperature of the area bounded by the $-30^{\circ} \mathrm{C}$ isotherm at $500 \mathrm{mb}$ ) and zonal available potential energy (arbitrary units) for years indicated by

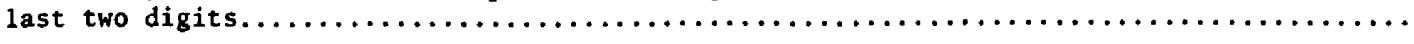


Fig. 18

Fig, 19

Fig. 20

Fig. 21

Fig. 22

Fig. 23

Fig. 24

Fig. 25

Fig. 26

Fig. 27

Fig. 28

Fig. 29

Fig. 30

Fig. 31

Fig. 32

Fig. 33

Fig. 34

Fig. 35

Fig. 36

Fig. 37

Fig. 38

Fig. 39

Fig. 40

Fig. 41

Fig. 42
Mean meridional temperature profiles at $500 \mathrm{mb}$ for years indicated by last two digits......

Average latitudinal position of the $-30^{\circ} \mathrm{C}$ isotherm at $500 \mathrm{mb}$ during January as a function

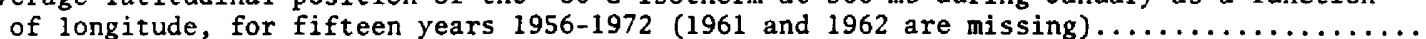

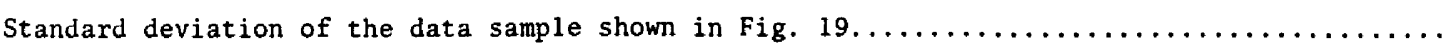

Heat flux across $60^{\circ} \mathrm{N}$ and the latitudinal position of the $-30^{\circ} \mathrm{C}$ isotherm at $500 \mathrm{mb}$ and at

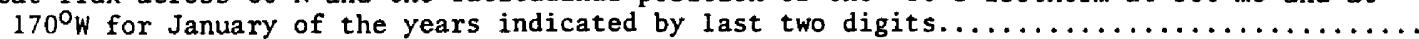

Mean January surface temperature at Moscow, USSR, and the latitude of the $-30^{\circ} \mathrm{C}$ isotherm

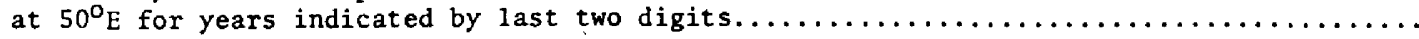

Mean January surface temperature at Pittsburgh, Pennsylvania and the latitude of the $-30^{\circ} \mathrm{C}$

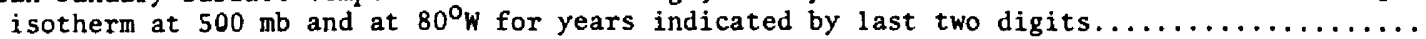

3 -day and 31-day running means of zonal available potential energy (units $10^{5}$ joules/m $/ \mathrm{m}^{2}$ for the period October 1968 through April 1969 and for the region north of $20^{\circ} \mathrm{N}$ and the layer

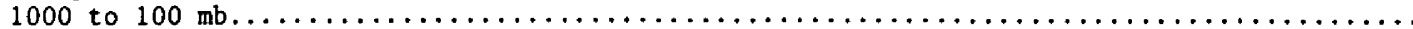

Same as Fig. 24 , except for eddy available potential energy $\ldots \ldots \ldots \ldots \ldots \ldots \ldots \ldots \ldots \ldots$

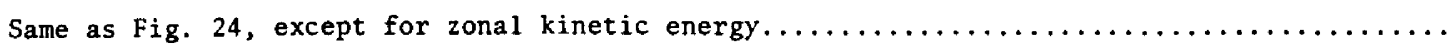

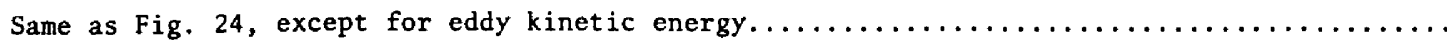

Same as Fig. 24, except for period October 1969 through April 1970, zonal available

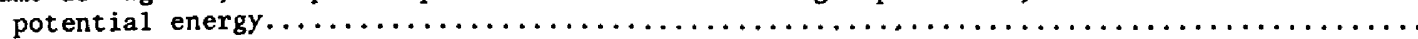

Same as Fig. 28, except for eddy available potential energy $\ldots \ldots \ldots \ldots \ldots \ldots \ldots \ldots \ldots \ldots$

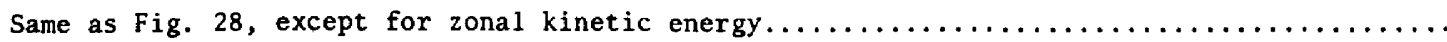

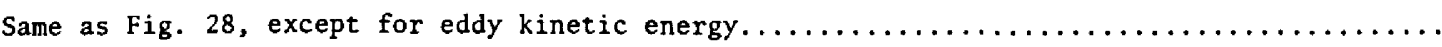

Same as Fig. 24, except for period October 1970 through April 1971, zonal available

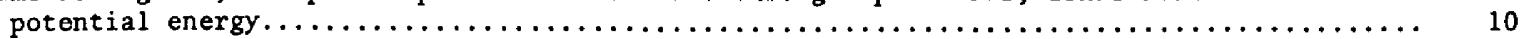

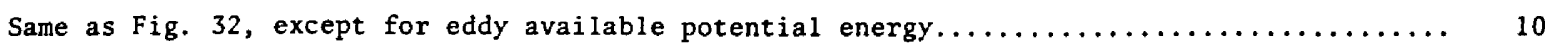

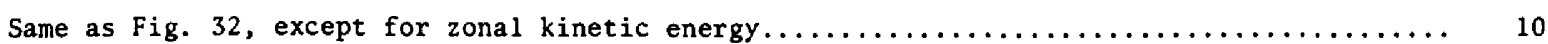

Same as Fig. 32 , except for eddy kinetic energy $\ldots \ldots \ldots \ldots \ldots \ldots \ldots \ldots \ldots \ldots \ldots \ldots \ldots \ldots \ldots \ldots \ldots \ldots \ldots$

Deviations of the 3-day average energy modes from their 31-day averages for the period

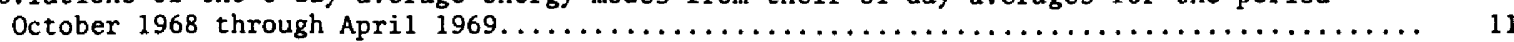

Same as Fig. 36, except for time period October 1969 through April $1970 \ldots \ldots \ldots \ldots \ldots \ldots$

Same as Fig. 36, except for time period October 1970 through April $1971 \ldots \ldots \ldots \ldots \ldots$

Mean spectral power density of energy modes averaged over three winter seasons (October

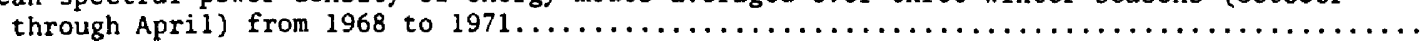

Coherence and spectral gain of zonal available potential energy (AZ) and eddy kinetic energy

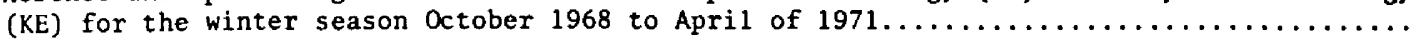

Mean meridional temperature profile of the layer 1000 to $100 \mathrm{mb}$, and mean temperature change of spherical section north of $20^{\circ} \mathrm{N}$ for selected days surrounding a typical mid-winter decrease in $\mathrm{AZ}$. The dashed line provides an arbitrary constant temperature profile......

Atmospheric energy transformations (see Reiter, 1969). There seems to be a feedback mechanism acting between $\mathrm{KE}$ and the transformation $<\mathrm{AZ}, \mathrm{AE}>\ldots \ldots \ldots \ldots \ldots \ldots \ldots \ldots \ldots$

\section{ACKNOWLEDGMENTS}

The major support for the analysis work performed under the present investigation comes from NSF Grant GA-42215. An investigation of hemispheric circulation features, as an outgrowth of earlier work by Reiter and Macdonald (1973), was supported by the USAEC under Contract AT(11-1)-1340. A number of the calculations described herein were accomplished at the NCAR Computing Facility, which is totally funded by the National Science Foundation.

This publication is also listed as USAEC Report No. C00-1340-41 and as Colorado State University Atmospheric Science Paper No. 232. 


\title{
ON THE VARIABILITY OF HEMISPHERIC SCALE ENERGY PARAMETERS
}

\author{
by \\ J.P. McGuirk, E.R. Reiter \& A.M. Barbieri \\ Atmospheric Science Department \\ Colorado State University \\ Fort Collins, Co.
}

\section{ABSTRACT}

Hemispheric scale energy parauleters have been computed and their variability on an annul time scale and a scale of a few weeks is identified and discussed.

Based on data for 15 winter seasons, the annual variability of available potential energy is linked to fluctuations of elements of the general circulation, such as the jet streams. This link establishes a relationship between simply computed hemispheric scale parameters and regional weather conditions affecting man's economic well being.

Daily statistics on three winter seasons of hemispheric energy modes have been analyzed with the ultimate goal of understanding and reproducing the behavior of the hemispheric energy cycle. Two phenomena are discussed:

(1) A strong 22-26 day cycle in the energy modes which may be linked to synoptic scale systems and the atmospheric index cycle; and

(2) A large midwinter "dip" in zonal available potential energy which is tentatively linked to a possible movement of the Hadley cell. This "dip" is shown to have a profound effect on the meridional temperature gradient, particularly in midlatitudes.

\section{INTRODUCTION}

The world food production, under the stress of an exponentially increasing world population and of vastly increased prices for energy, has become a focal point of concern. This concern was heightened by reports that indicate a deterioration of climatic conditions in the middle and high latitudes of the northern hemisphere where most of the world's agricultural activities are concentrated. All of a sudden we have come to realize that global and national economies are rather sensitive to the vagaries of weather and climate. To illustrate this point, the spectrum of kinetic energy of the zonal wind component has been plotted in Fig. I (after Vinnichenko and Dutton, 1969), together with crude estimates of dollar losses sustained by adverse effects of atmospheric variability. This variability is given in terms of a space scale (upper part of diagram) and a time scale (lower part of diagram). Economic loss estimates of prolonged drought or flood disasters are made on a hemispheric, not national, basis; so are the estimates for a severe climatic deterioration.

Moderate climatic changes have been experienced during recorded history, especially in the middle and high latitudes of the northern hemisphere. The temperature regime in this region of the globe during the $1940^{\prime} \mathrm{s}$ was the mildest on record within the time span of the last millennium (Fig. 2). A spectacular amelioration of climatic conditions occurred between the $1880^{\prime} \mathrm{s}$ and the middle of the present century (see e.g., Kellogg and Schneider, 1974). This improvement in climatic conditions is also reflected in the extent of sea-ice coverage of the North Atlantic (Fig. 3).

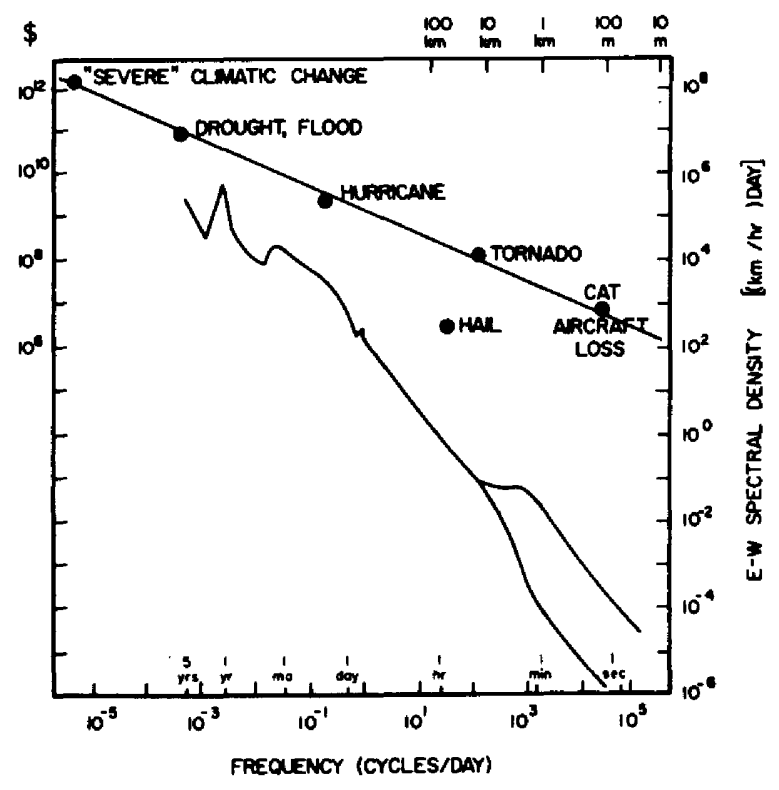

Fig. 1. Spectrum of the kinetic energy of the zonal wind component (after Vinnichenko and Dutton, 1969) units of [ $\left(\mathrm{km}^{2} / \mathrm{hr}^{2}\right)$ day] labelled on right side of diagram, and approximate dollar values of weatherrelated disasters (partly after Maunder, 1970), labelled on left side of diagram. 


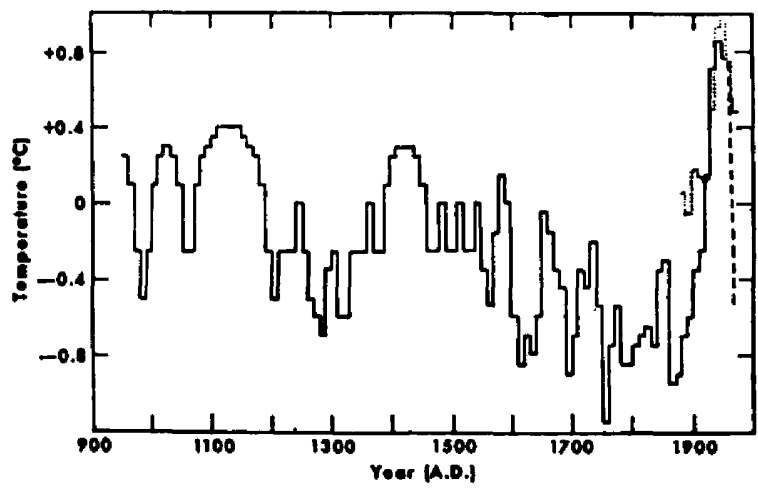

Fig. 2. Mean annual temperature in Iceland over the past millennium. (Data courtesy of $P$. Bergthorsson.) Dashed line shows the rate of decline in the period 1961 to 1971, dotted line indicates the variation of mean temperature in the northern hemisphere plotted to the same scale (from Bryson, 1974a).

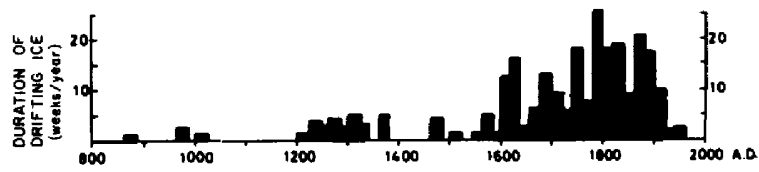

Fig. 3. Duration of drifting ice near the coasts of Iceland in units of weeks per year (after Koch, 1945, from Flohn, 1973).

It has been pointed out by Korff and Flohn (1969) that changes in the temperature of the polar regions can lead to adjustments in the meridional temperature gradient if the tropical regions do not undergo the same temperature trend. This, in turn, will lead to adjustments in the general circulation of the atmosphere, specifically in the position of the subtropical high-pressure belt. This belt will undergo a northward shift with a decreasing meridional temperature gradient (Fig. 4). We witness such a migration of the subtropical anticyclones with the progression of seasons each year from winter to summer. The climatic changes indicated in Fig. 2, of course, are much more subtle than the seasonal changes of weather patterns. Nevertheless, they are expected to leave an imprint on the behavior of the general circulation of the atmosphere.

One region of the globe where weather patterns are strongly dependent upon the seasonal migration and position of the subtropical anticyclonic belt is the Indian subcontinent. The "burst" of the summer monsoon in India, Pakistan, and Bangladesh depends on the establishment of a quasi-permanent high-pressure regime in the upper troposphere over Tibet, the shift of the westerly subtropical jet from northern India into Mongolia and China, and the establishment of an easterly jet stream over India (Koteswaram, 1958. [For a detailed discussion see Reiter, 1969b]). With a "climatic trend" by the subtropical anticyclones to undergo a poleward shift one would expect the Indian summer monsoon to burst somewhat earlier than usual; to be less susceptible to "breaks" (i.e., interruptions of the monsoonal flow patterns caused by a weakening of the anticyclone over Tibet and of the easterly flow regime over India); and to "retreat" later than normal in autum. The sum-total of these effects will lead to increased precipitation over the Indian subcontinent during the summer monsoon season. This is reflected in Fig. 5 which shows an abnormally low drought occurrence in India during the favorable climate period of the 1940 's and 1950's.

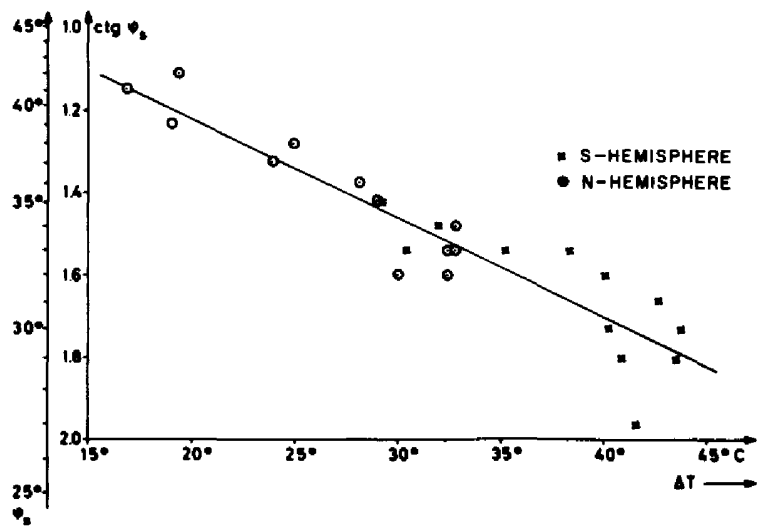

Fig. 4. Correlation between geographic '1atitude $\left(\phi_{S}\right)$ of the subtropical high-pressure belt and the mean tropospheric $(300-700 \mathrm{mb})$ temperature gradient between equator and pole (after Korff and Flohn, 1969, from Flohn, 1973).

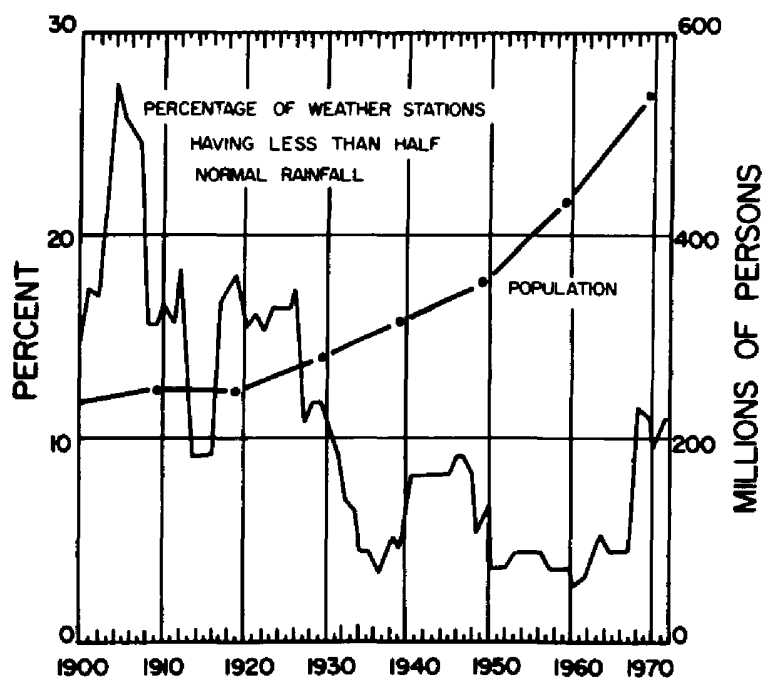

Fig. 5. Trends in the percentage of weather stations in northwestern India reporting less than half of usual rainfall in a given year. Overlapping ten-year averages (from Bryson, 1974b).

Another region of concern is the Sahel stretching along the southern rim of the Sahara desert. This region also depends on the rainfall during the summer season which originates from the moist monsoonal air currents carried inland south of the intertropical convergence zone (ITCZ) (Fig. 6). Where the ITCZ surface intersects with the earth's surface, the moist monsoonal air layer is too shallow to permit the development of convective thundershowers that penetrate into the convectively unstable, but dryer, layer aloft. Only at 
some distance south of the ITCZ intersection line with the ground will there be abundant rainfall triggered by traveling disturbances in the easterly flow aloft MbeleMbong, 1974).

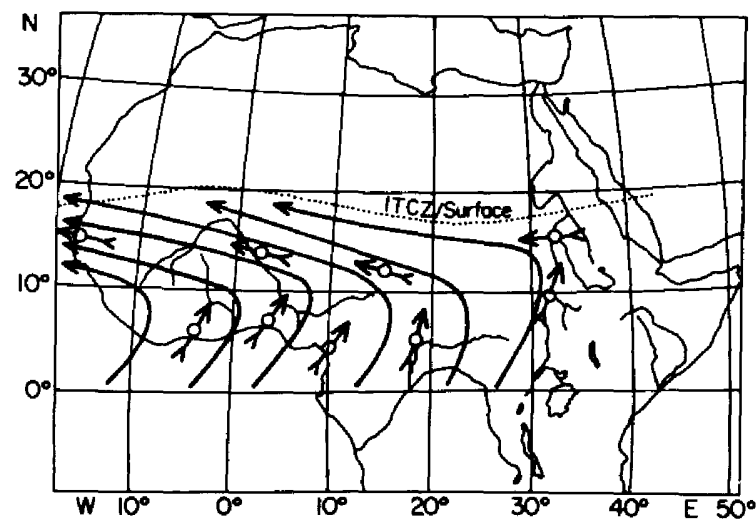

Fig. 6. Extent of monsoonal flow over Central Arica (from Bryson, 1974c).

With a "climatic" northward shift of the subtropical high-pressure belt, the African ITCZ will follow suit. The climatic optimum during the $1950^{\prime} \mathrm{s}$ brought adequate amounts of rainfall to the Sahel. This is reflected in the water level of Lake rhad, as well as in the Nile run-off (Fig. 7).

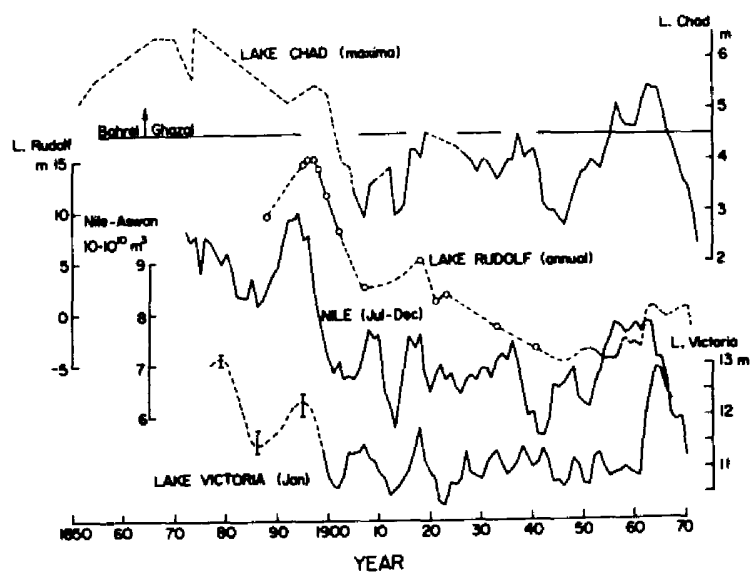

Fig. 7. Lake leveis of Lake Chad, Lake Rudolf and Lake Victoria, and run-off of the Nile $a^{t}$. Aswan (from Bryson, 1974c).

\section{The Recent Hemispheric Cooling Trend}

The dense observational network in the northern hemisphere which was established in the late 1940's permits an assessment of hemispheric temperature trends. It appears that a cooling trend, especially noticeable in high latitudes, had set in around 1960 (Figs. 8 and 9) (see also Rodewald, 1972). This trend was studied in detail by Starr and Oort (1973) using the northern hemisphere upper-air data between 1958 and 1963 carefully processed at MIT.

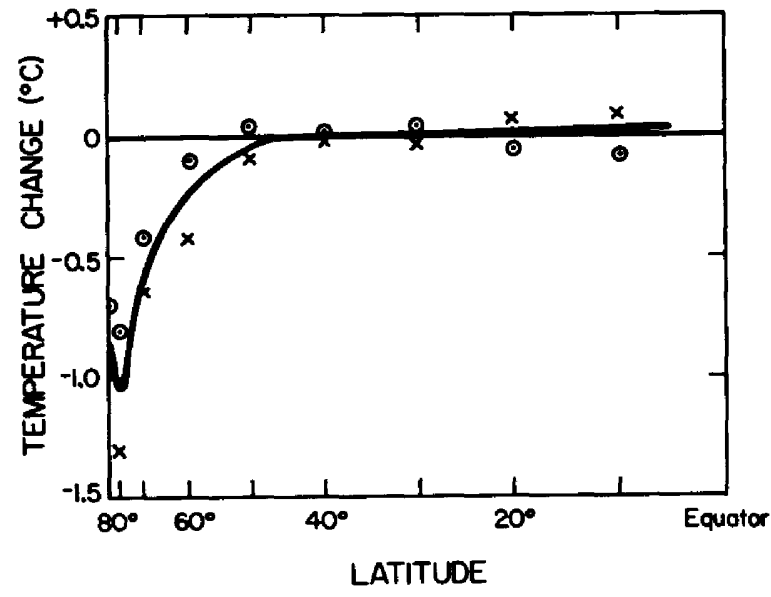

Fig. 8. Departures of the mean temperatures fo: the decade 1961-1970 from the mean temperaturcs 1931-1960 (from Flohn, 1973).

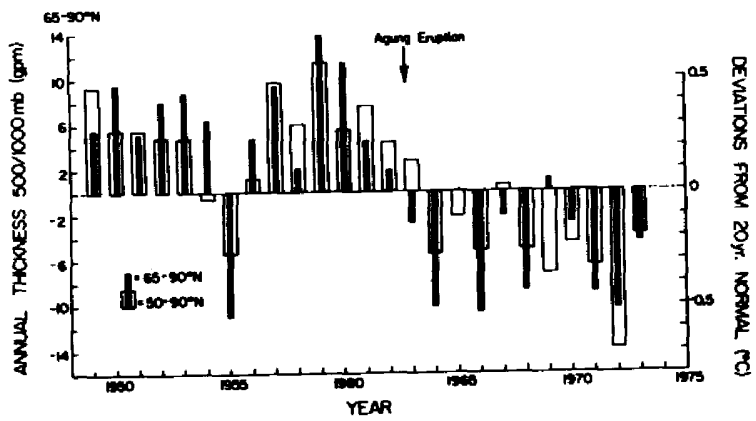

Fig. 9. Annual nean values of the thi:kness $500^{\prime} 100 \mathrm{mb}$ in the latitude regions $65-90 \% \mathrm{~N}$, and $50-90^{\circ} \mathrm{N}$, expressed as departures from the 20 year normal values (1953-1972) (from Bryson, 1974r)

The consequences of this trend have been seen to reverberate through the precipitation regimes over India (Fig. 5) and the Sahel. The Sahelian drought, which apparently peaked in 1972, is still fresh in our minds, Unfortunately, agricultural practices and the increase in population (see also Fig. 5) adjusted to the climatic optimum of the 1940's and 1950's. Re. adjustment to a somewhat harsher climate will bring grave economic, social and political stresses, not only to the areas immediately affected by adverse precjpitation trends but also to the world at large which has not yet learned how to stabilize its demand for nonrenewable resources.

Alarmed by the prospects of a deteriorating climate, and by the suggestions made by several scientists that this deterioration originated from such anthropogenic causes as air pollution by suspended particulates, we decided to check the northern hemisphere temperature trend with our NMC data bank. These data are less carefully screened than the "MIT period" of five years, but they offer the advantage of a longer time record which, eventually, will be brought up to current.* (Unfortun-

*We are indebted to NCAR for supplying us with copies of the NMC tapes. Dr.R.F. Adler, now with NASA Goddard Space Flight Center, performed the original analyses of the hemispheric temperature trends. Mrs. Alice Fields was in charge of programming and computer processing of the data. 
ately the data tapes for 1961 and 1962 could not be vitained. Thus, a gap exists in our analyses for these two years.)

Fig. 10 reveals temperature variations at $500 \mathrm{mb}$ for the winter months and for the "cold season" which are quite similar to those shown in Fig. 9. Especially the "precipitous" decline between 1959 and 1963 , the slight recovery between 1964 and 1968 , and the further decline until 1972 are well reflected.

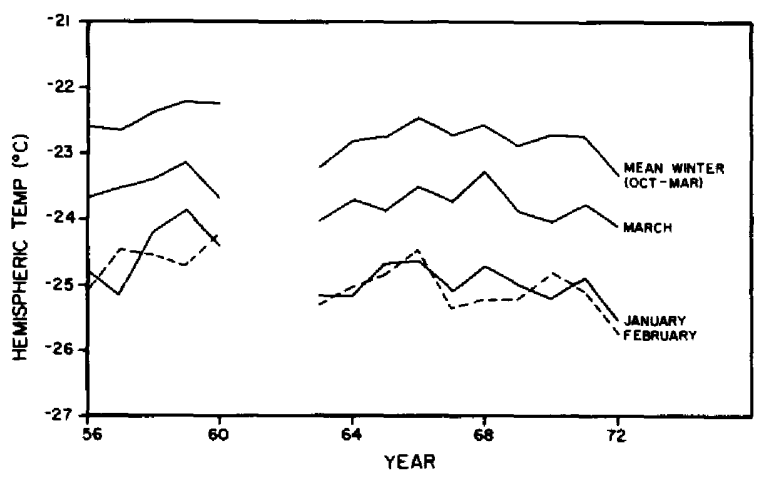

Fig. 10. Mean hemispheric temperatures north of $200 \mathrm{~N}$ at $500 \mathrm{mb}$.

From Fig. 11 we can see that the mid-winter cooling trend was strongest at high latitudes, especially between 1959 and 1964. The mid-1atitude belt between $30^{\circ} \mathrm{N}$ and $60^{\circ} \mathrm{N}$ also reveals a slight irregular cooling trend between 1959 and 1972 for January and for the cold season, less so for March (Fig. 12). This trend is less pronounced here than at high latitudes (Fig. 11). From this we should expect a gradual increase of the zonal available potential energy in the norther ${ }_{1}$ hemisphere and, as a consequence, a strengthening of the westerly circulation in the jet stream belt of middle latitudes, together with a slight southward shift of this belt.

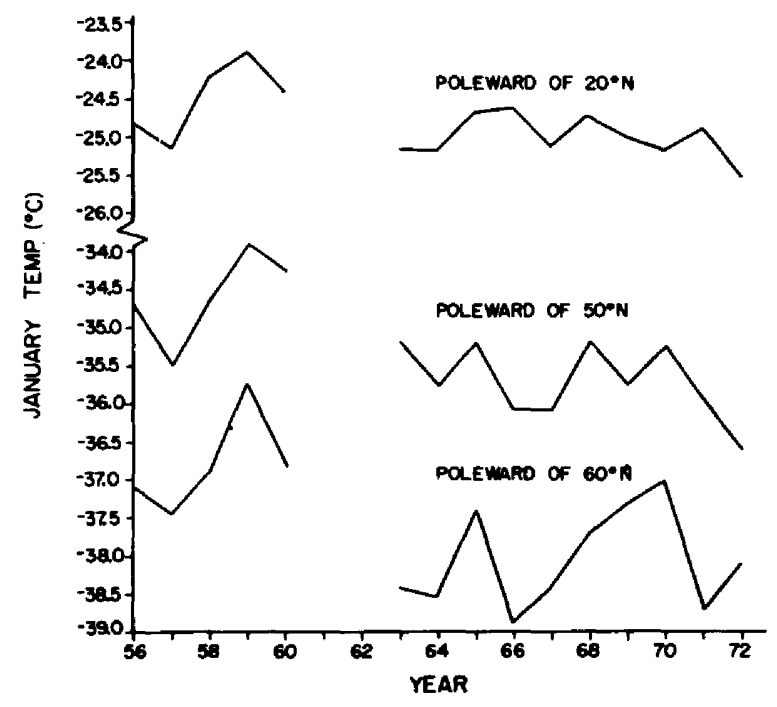

Fig. 11. Mean January temperatures for various spherical segments of the northern hemisphere.

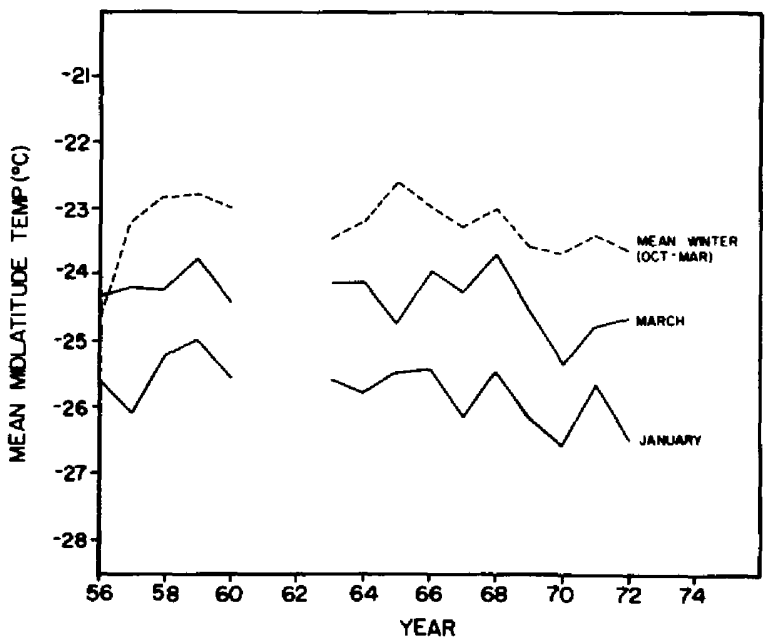

Fig. 12. Mean temperatures for latitude belt $30^{\circ} \mathrm{N}$ to $60^{\circ} \mathrm{N}$ for time pariods as indicated.

The zonal available potential energy, averaged over the month of January, underwent large interdnnual fluctuations within the time period 1956-1972 as shown in Fig. 13. Discounting these fluctuations, an increasing trend is noticeable, in agreement with our hypothesis stated earlier. The zonal kinetic energy, on the other hand, does not reveal a significant longterm trend, although analysis of kinetic energy only at $500 \mathrm{mb}$ does not allow us to say with any certitude that a long-term trend does not exist. The eddy-available potential and kinetic energies (Fig. 14) reveal no significant trends either, except that during the two years of missing data (1961 and 1962) a significant increase in both energies seemed to have occurred. The cooling trend which was relatively steep during this short time period (Fig. 11) might have led to an adjustment in the general circulation resulting in an increased planetary wave activity.

In order to check the hypothesis that the cooling trend in high latitudes might have resulted in a southward shift of the jet stream belt, we computed the "cold-pool area" bounded on its equatorward side by the position of the polar front. After an inspection of a large number of daily $500-\mathrm{mb}$ maps we decided that the location of the $-30^{\circ} \mathrm{C}$ isotherm at this pressure level adequately defines the mean position of the polar front during the cold season (see also Palmen and Newton, 1969; Reiter and Macdonald, 1973; Reiter, 1975).

The upper part of Fig. 15 shows the results of our computations for January. Indeed, we find a somewhat irregular trend between 1959 and 1972 that suggests a gradual increase of the area inside the $-30^{\circ} \mathrm{C}$ isotherm at $500 \mathrm{mb}$. This can be interpreted as a slight equatorward shift of the polar front and its associated jet stream.

The area-weighed mean temperature inside the $-30^{\circ} \mathrm{C}$ isotherm at $500 \mathrm{mb}$ defines the "cold-pool temperature." This parameter, computed for the month of January, is shown in the lower part of Fig. 15. Two facts become apparent: There exists a reasonably good correlation between the cold-pool temperature and the hemispheric mean temperature poleward of $50^{\circ} \mathrm{N}$ (middle curve in Fig. 11 , see also Fig. 16). Secondly, the sporadic interannual fluctuations of the cold-pool temperature and the cold-pool area (lower and upper curves in Fig. 15) 
are poorly correlated with each other. Thus, there are winters -- or, more properly, Januaries -- when the cold pool is large but relatively warm, and other winters when it is relatively cold.
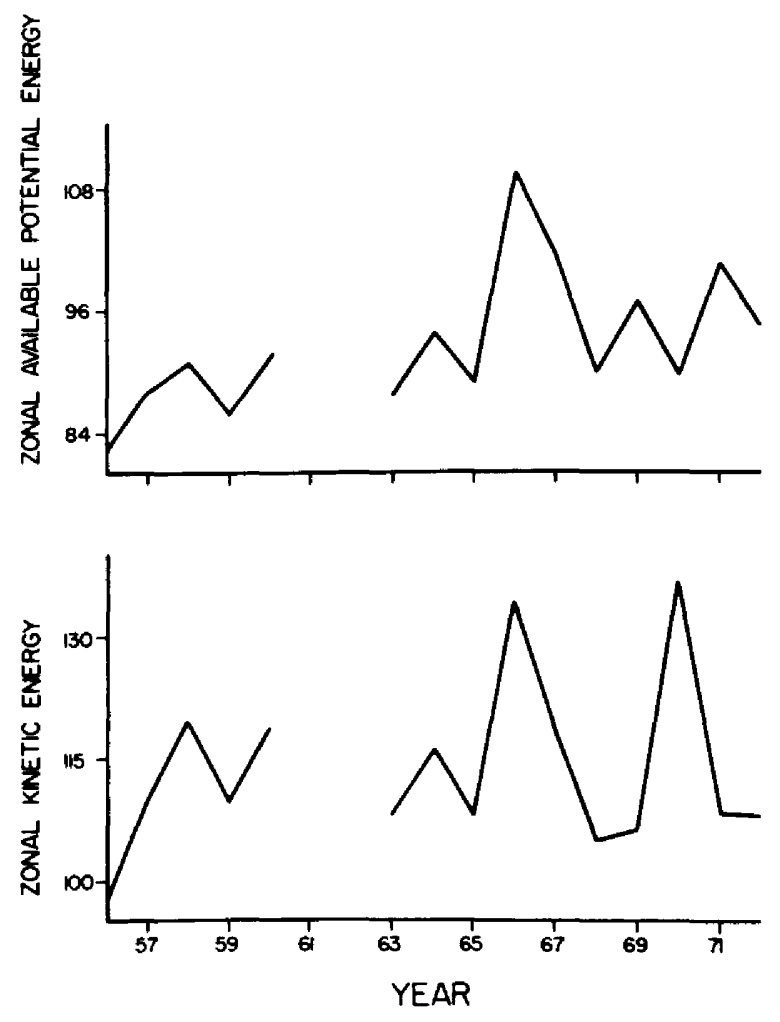

Fig. 13. Mean zonal available potential and kinet $1 \mathrm{c}$ energies (arbitrary units) for January, computed for the northern hemisphere poleward of $20^{\circ} \mathrm{N}$ and for the 500-mh layer.

The correlation between mean cold-pool temperature in January and mean zonal available potential energy scatters considerably. All data points for the period under investigation lie to the right of line shown in Fig. 17, which appears to set a limiting condition between the cooling of the polar regions and the buildup of hemispheric potential energy.

In Fig. 18 we have plotted the mean meridional temperature profiles at $500 \mathrm{mb}$ for the months of January 1956 to 1972 ( 1961 and 1962 are missing). It is easily seen that the largest interannual variability is confined to high latitudes, 1963 showing the coldest conditions there. In middle latitudes, on the other hand, January of 1972 established the cold record for the period under investigation. During this year the entire meridional temperature gradient was confined to latitudes south of $65^{\circ} \mathrm{N}$. We should expect, therefore, that the jet-stream activity during this winter month also had shifted relatively far to the south. We should recall that this year was characterized by a severe drought in the Sahel. Drought conditions also were wide spread in India.

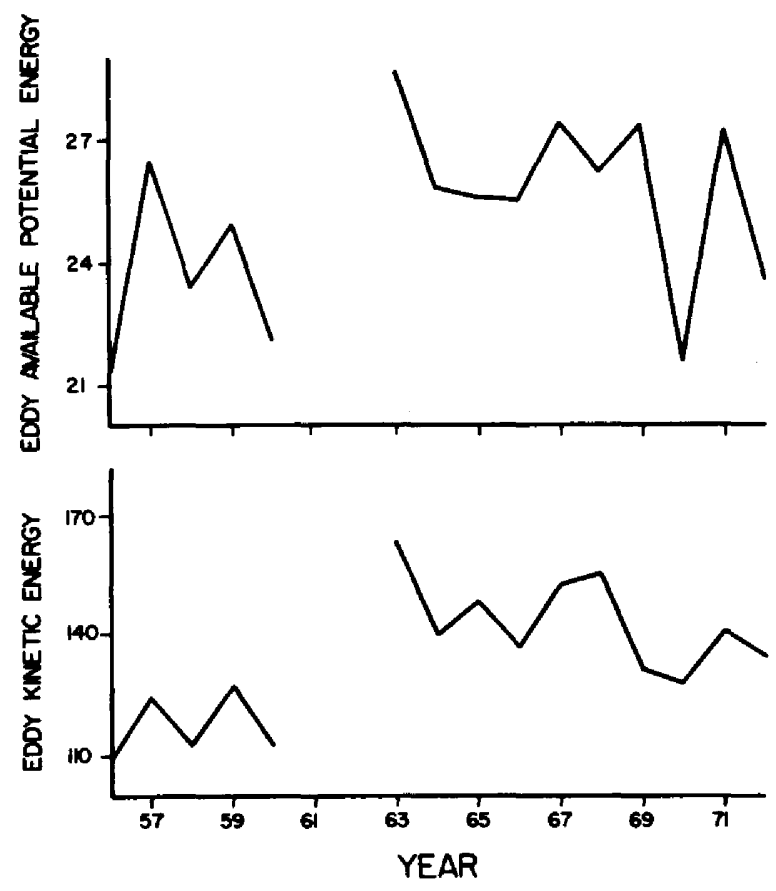

Fig. 14. Mean eddy available potential and kinetic energies (arbitrary units) for January, computed for the northern hemisphere poleward of $200 \mathrm{~N}$ and the 500-mb layer.
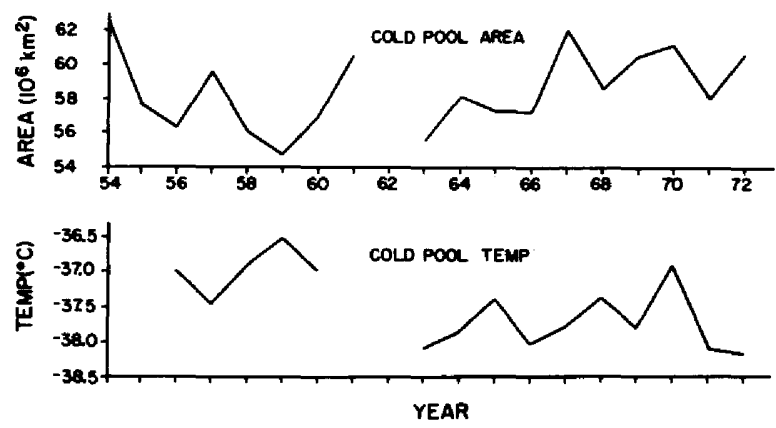

Fig. 15. Area of the cold pool $\left(10^{6} \mathrm{~km}^{2}\right)$ bounded by the $-30^{\circ} \mathrm{C}$ isotherm at $500 \mathrm{mb}$, and mean areaweighted temperature of this area at $500 \mathrm{mb}$. 


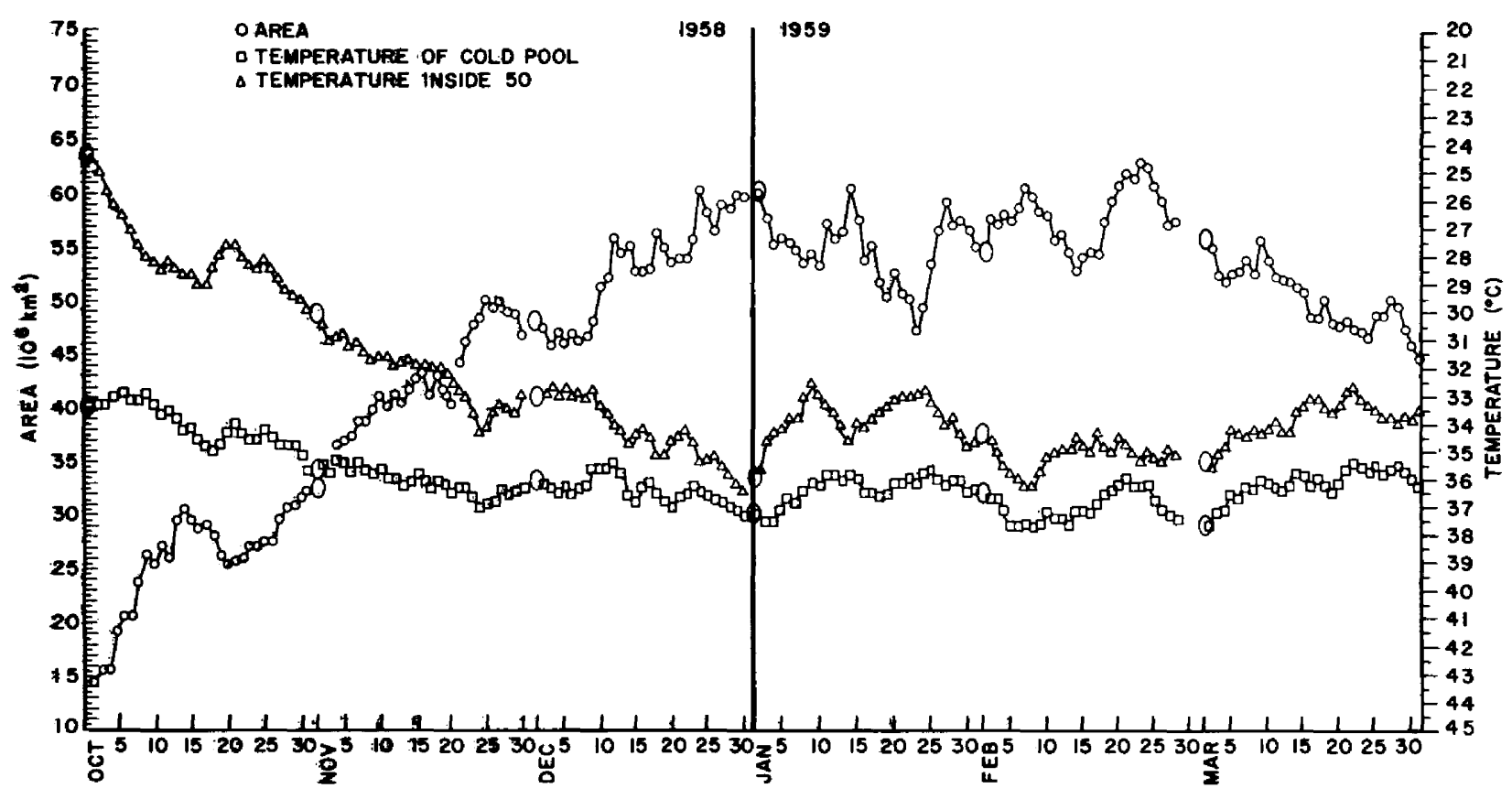

Fig. 16. Daily values for the 1958-1959 cold season of the cold-pool area at $500 \mathrm{mb}$ (i.e., the area bounded by the $-30^{\circ} \mathrm{C}$ isotherm at $500 \mathrm{mb}$ ), the area-weighted temperature of this area at $500 \mathrm{mb}$, and the mean temperature of the spherical segment north of $50{ }^{\circ} \mathrm{N}$.

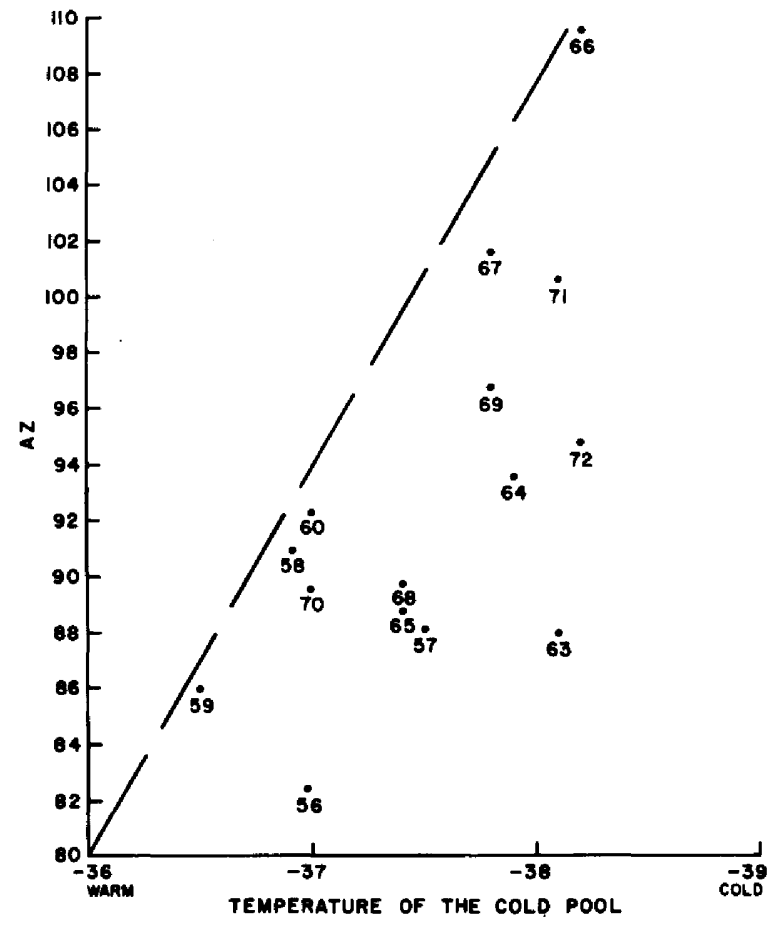

Fig. 17. Mean cold-pool temperature (i.e., mean temperature of the area bounded by the $-30^{\circ} \mathrm{C}$ isotherm at $500 \mathrm{mb}$ ) and zonal available potential energy (arbitrary units) for years indicated by two digits.

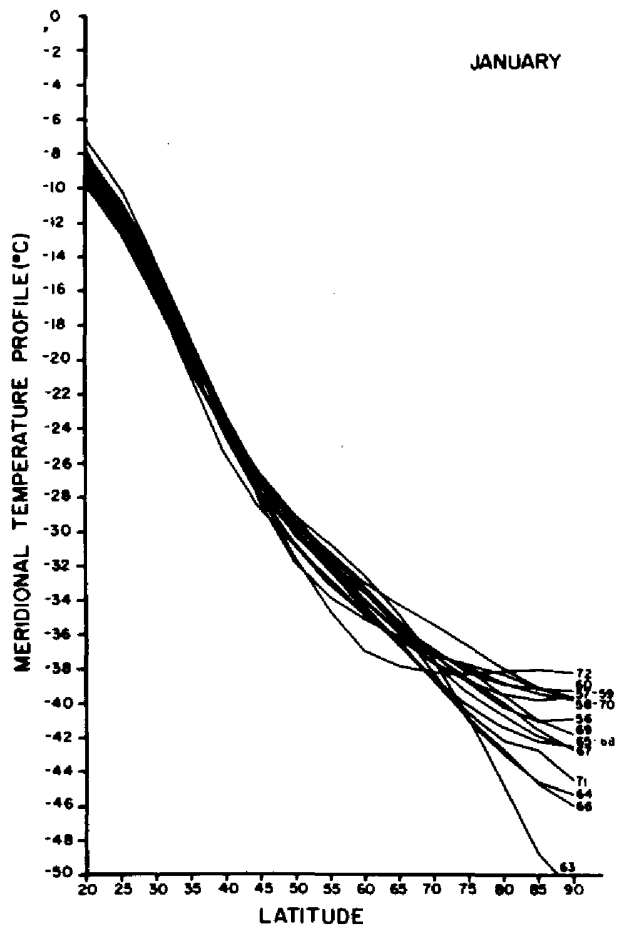

Fig. 18. Mean meridional temperature profiles at $500 \mathrm{mb}$ for years indicated by last two digits. 


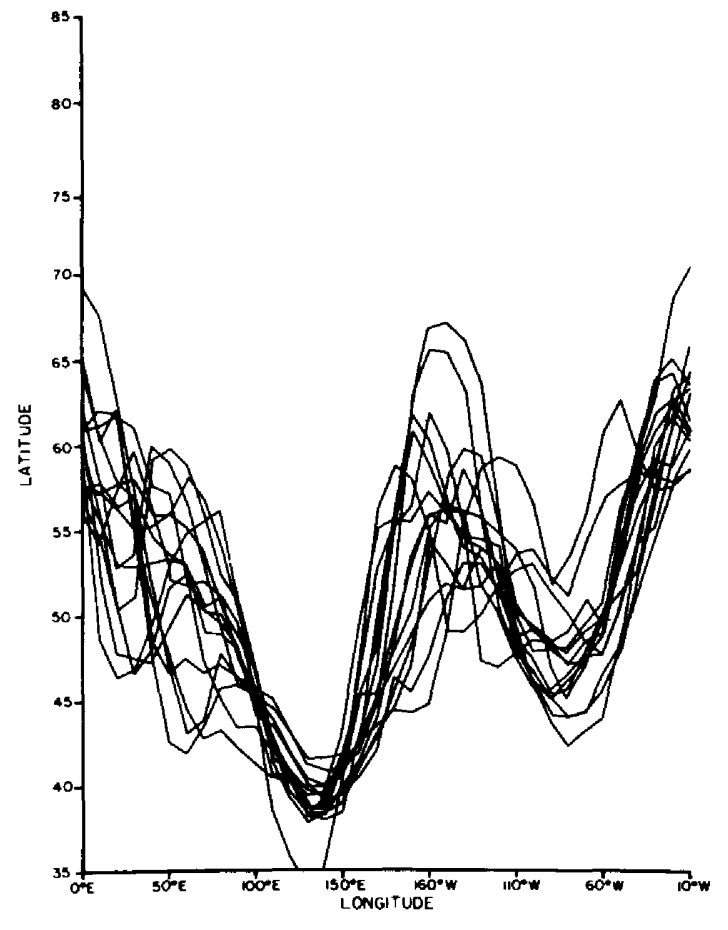

Fig. 19. Average latitudinal position of the $-30^{\circ} \mathrm{C}$ isotherm at $500 \mathrm{mb}$ during January as a function of longitude, for fifteen years 1956-1972 (1961 and 1962 are missing).

\section{Regional Effects}

Starr and Oort (1973) and Landsberg and Albert (1975) showed that the temperature trend experienced in the northern hemisphere during recent history did not spread uniformly around the globe. The warming that took place between the latter part of the 19th century and the "normal period" of 1941-1970 was confined in the North American sector to the U. S. Rocky Mountain States and to the Midwestern "cornbelt" between Nebraska and Indiana. Surface temperature rises of over $2^{\circ} \mathrm{C}$ were observed in these regions, whereas most of the southwestern United States and the Pacific coastal regions remained unaffected by this warming trend.

Landsberg and Albert (1975) furthermore showed that a change in annual mean temperatures can have a profound effect on the length of the freeze-free growing season, especially in regions with strong topographic structuring. In Oregon, for instance, a twodegree $r i s e$ in the annual mean temperature would result in an average increase of more than 50 days in the length of the growing season. In North Dakota, on the other hand, a similar change in mean temperature would produce a change in the growing season of perhaps only 10 days.

If the long-term warming and cooling trends reveal marked regional preferences, we have to suspect the same for the interannual variability of the "cold pool" of the northern hemisphere. This regional behavior can be expressed by the variation in latitude at which the $-30^{\circ} \mathrm{C}$ isotherm at $500 \mathrm{mb}$ occurs at different longitudes. Average latitude positions of this isotherm during January are shown in Fig. 19. The standard deviation in the latitudinal fluctuations of this isotherm for the 15-year period 1956-1972 and for the average of January, is shown in Fig. 20 (1961 and 1962 missing).

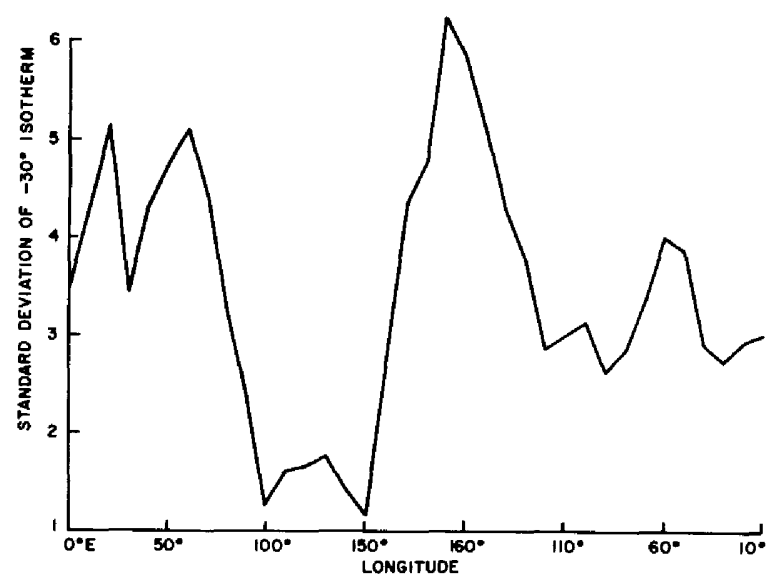

Fig, 20. Standard deviation of the data sample shown in Fig. 19.

Minimum variability is found between $100^{\circ} \mathrm{E}$ and $150^{\circ} \mathrm{E}, \mathrm{i} . \mathrm{e}$, , in the Mongolian and Japanese longitude sector. Here, apparently, minor climatic trends in the hemispheric winter-time temperature regimes will have little regional impact.

Maximum variability is found over the Pacific Ocean in the Guld of Alaska at $160^{\circ} \mathrm{W}$. We have to sus pect that the interannual variability of the mean January position of the polar front in this region, together with regional sea-surface temperature anomalies (see e.g., Namias, 1969) might produce an interannually variable forcing of the general circulation, albeit small, through the sensible and latent heat input into the atmosphere. This forcing, if it is present to a significant degree, is expected to be of a rather complex nature and should be most effective in the lower troposphere. An at tempt to correlate the meridional heat flux at $60^{\circ} \mathrm{N}$ and at $500 \mathrm{mb}$ in this region of the Pacific with the latitudinal position of the $-30^{\circ} \mathrm{C}$ isotherm at $170^{\circ} \mathrm{W}$ reveals a tendency for decreased flux as the polar front moves to the south of this parallel circle (Fig. 21). The data points for January 1958 and 1967 disturb this trend. During these months the $-30^{\circ} \mathrm{C}$ isotherm was found exceptionally far to the south, indicating the presence of strongly anomalous synoptic conditions in the Gulf of Alaska.

A correlation attempt as shown in Fig. 21 , in retrospect, is not the best in considering regional forcing effects on the atmospheric circulation. If seasurface temperature anomalies, together with atmospheric circulation anomalies, were indeed producing a noticeable effect on atmospheric energetics or on flow patterns, we should expect to find such effects more pronounced downstream, perhaps over North America, than in the same longitude sector. This aspect remains to be investigated. At this point of our investigation we can only stress the large interannual temperature variability in the Gulf of Alaska during January.

From Fig. 20 it also appears that large interannual variations of the $-30^{\circ} \mathrm{C}$ isotherm at $500 \mathrm{mb}$ and during January exist near $60^{\circ} \mathrm{E}$ and $60^{\circ} \mathrm{W}$. These longitudes intersect Kasakhstan and the Labrador coast, respectively. The agriculturally productive sector of the United States between $80^{\circ} \mathrm{W}$ and $100^{\circ} \mathrm{W}$ shows less interannual variability in the January temperature regime at $500 \mathrm{mb}$ than does the European sector, including the Ural Mountain region. We have not yet studied the 
possible effects of winter weather on agricultural crops, such as winter wheat, nor have we completed our analyses for the months characteristic of the planting, growing and harvesting seasons. Work along these lines is in progress, however. Results, if they are similar to those presented in Figs. 19 and 20 , might help in identifying those regions of the northern hemisphere where agricultural productivity might be most vulnerable to the interannual variability of weather regimes and to climatic trends.

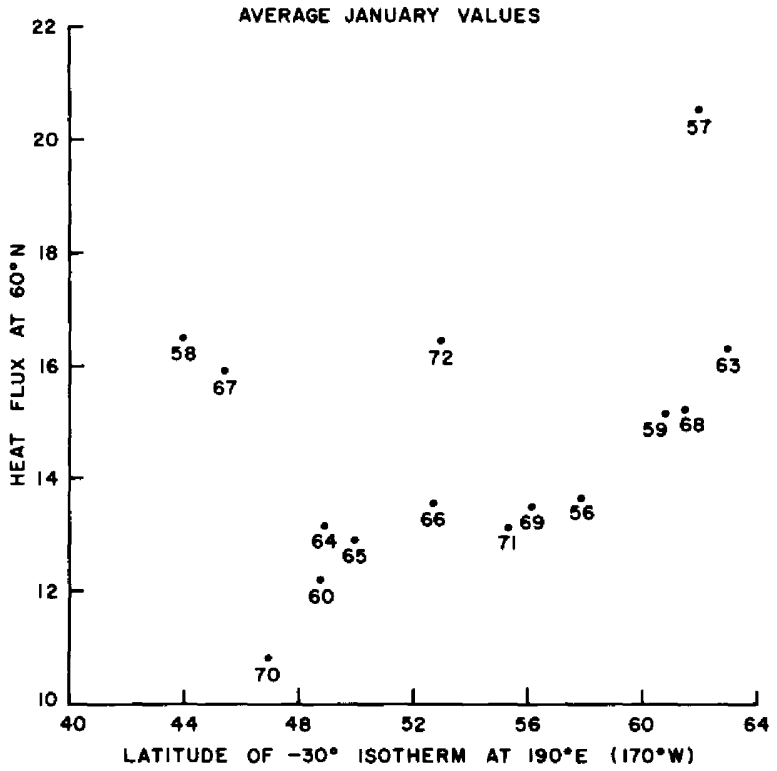

Fig. 21. Heat flux across $60^{\circ} \mathrm{N}$ and the latitudinal position of the $-30^{\circ} \mathrm{C}$ isotherm at $500 \mathrm{mb}$ and at $170^{\circ} \mathrm{W}$ fir January of the years indicated by last two digits.

We have to realize, of course, that the temperature regimes at the $500-\mathrm{mb}$ surface cannot be readily translated into an equivalent behavior of surface temperatures. Additional factors, such as cloudiness, snow cover, etc., exercise their influence on the heat budget, hence the temperatures of the lowest layers of the troposphere. A certain correlation between the 500-mb temperature regime and surface temperatures does exist however. From Fig. 22 we can see that the Moscow region shows a correlation between the latitude of the $-30^{\circ} \mathrm{C}$ isotherm at $500 \mathrm{mb}$ during January and the mean surface temperature of January, although the data points scatter considerably. Pittsburgh (Fig. 23) shows less scatter, especially for those years in which the meridional temperature gradient over the southern $U$. S. was relatively tight. The term "tight" is arbitrary in that the data were stratified into two categories: The eight years with the steepest meridional temperature gradient between $25^{\circ} \mathrm{N}$ and $30^{\circ} \mathrm{N}$ which were classified as "tight"; and the remaining seven years which were classified "loose."

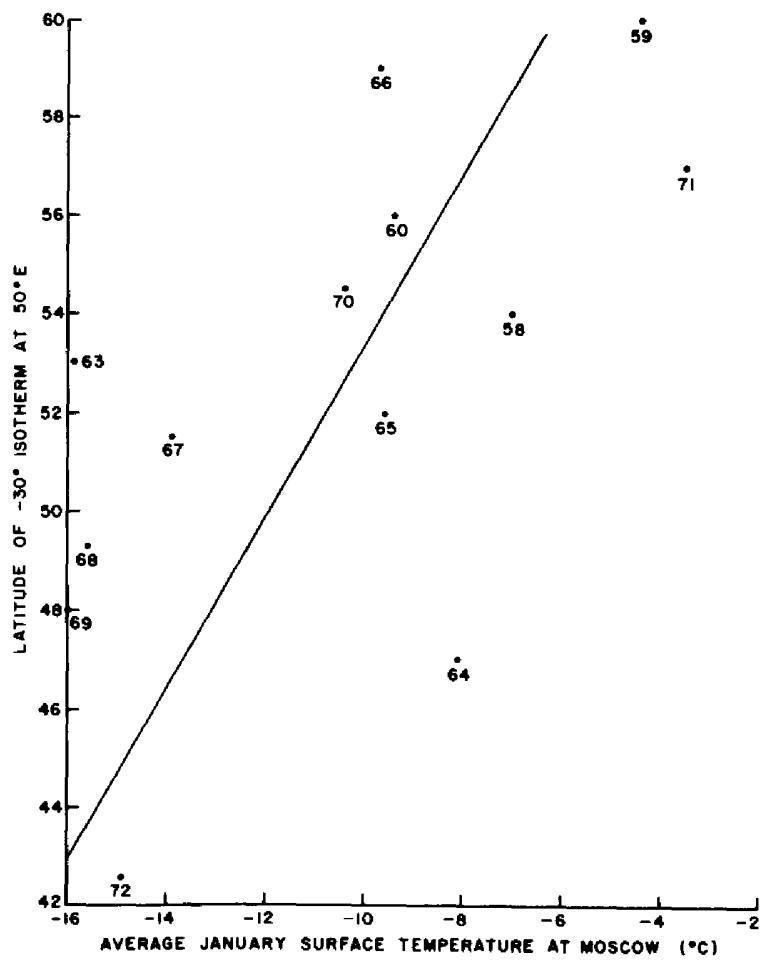

Fig. 22. Mean January surface temperature at Moscow, USSR, and the latitude of the $-30^{\circ} \mathrm{C}$ isotherm at $500 \mathrm{mb}$ and at $50^{\circ} \mathrm{E}$ for years indicated by last two digits.

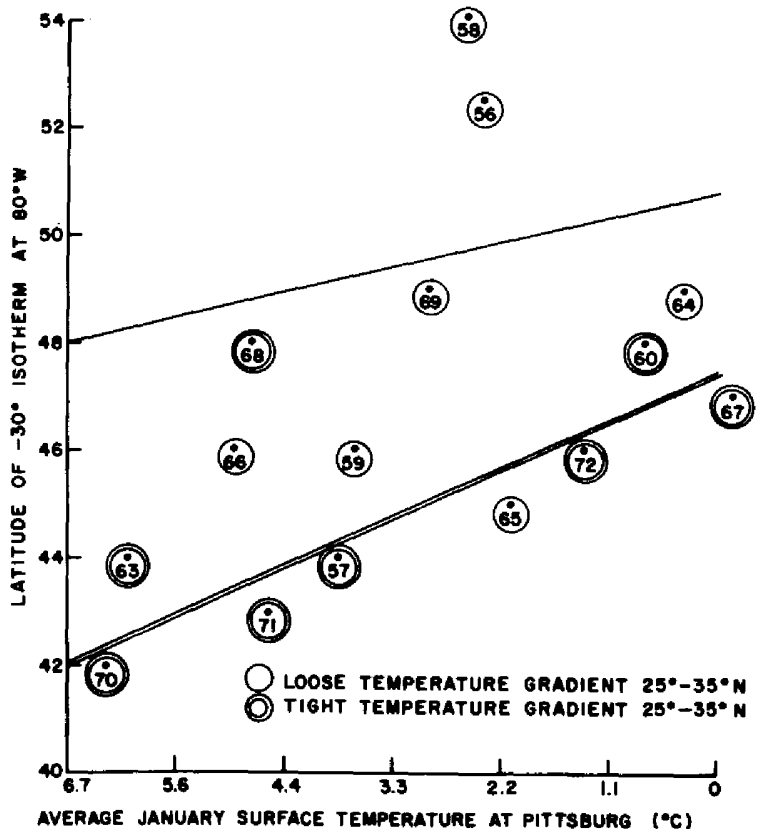

Fig. 23. Mean January surface temperature at Pittsburgh, Pennsylvania and the latitude of the $-30^{\circ} \mathrm{C}$ isotherm at $500 \mathrm{mb}$ and at $80^{\circ} \mathrm{W}$ for years indicated by last two digits. 


\section{Hemispheric Short Term Variability}

The zonal and eddy modes of the hemispherically averaged available potential and kinetic energies undergo rather large fluctuations during a single season. It is desirable to investigate these fluctuations for two reasons:

(i) The understanding of the interactions of these, energy modes within a season will be a powerful diagnostic tool in understanding long-range weather fluctuations.

(ii) Understanding the interannual variability in the seasonal behavior of these energy modes will bring us a step closer to the successful modeling of climatic trends.

Towards these ends we computed the four modes of energy for the cold seasons from NMC tapes. The energy parameters, in units of $10^{5}$ joules $/ \mathrm{m}^{2}$, were computed for the spherical segment north of $20^{\circ} \mathrm{N}$, and for the layer $1000 \mathrm{mb}$ to $100 \mathrm{mb}$. Three winter seasons, 1968 to 1971 , have been analyzed so far. Work is in progress to extend this analysis for the period 1963 to present. Typical data for zonal and eddy available. potential energy, and for zonal and eddy kinetic energy are shown in Figs. 24 to 35. Three-day and thirty-one-day, unweighted running averages were used as a simple highpass and low-pass filtering technique. We avoided using monthly average values because they may obscure significant short-term fluctuations in the data.

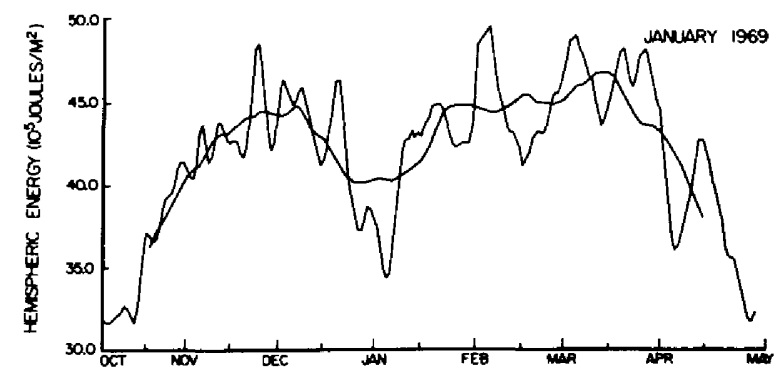

Fig. 24. 3-day and 31-day running means of zonal available potential energy (units $10^{5}$ joules $/ \mathrm{m}^{2}$ ) for the period October 1968 through April 1969 and for the region north of $20^{\circ} \mathrm{N}$ and the layer 1000 to $100 \mathrm{mb}$.

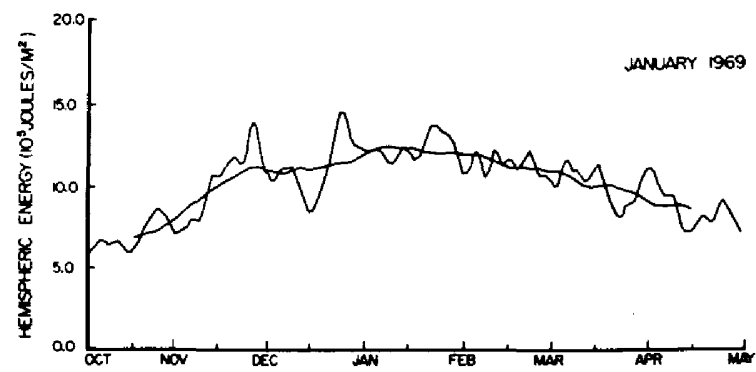

Fig. 25. Same as Fig. 24, except for eddy-available potential energy.

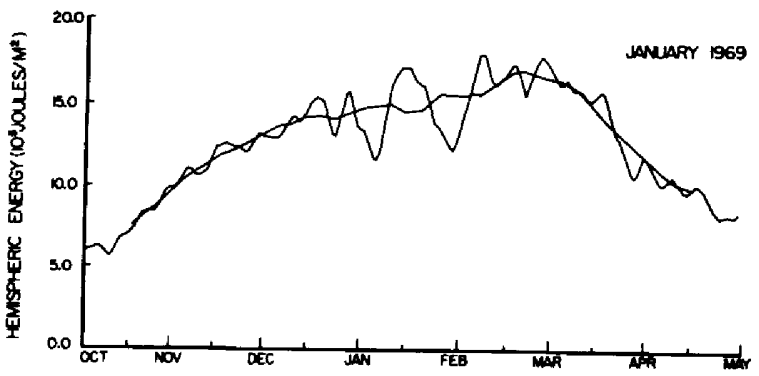

Fig. 26. Same as Fig. 24, except for zonal kinetic energy.

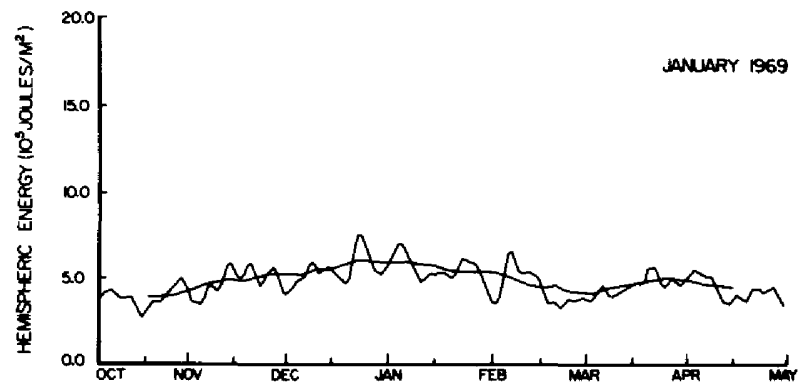

Fig. 27. Same as Fig. 24, except for eddy kinetic energy.

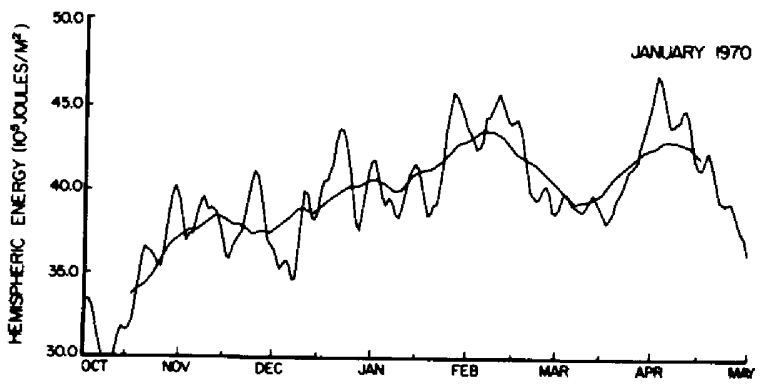

Fig. 28. Same as Fig. 24, except for period October 1969 through April 1970, zonal available potential energy.

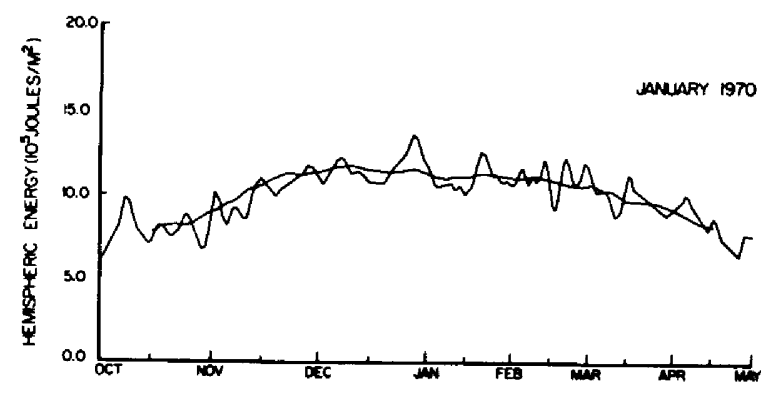

Fig. 29. Same as Fig. 28, except for eddy-available potential energy. 


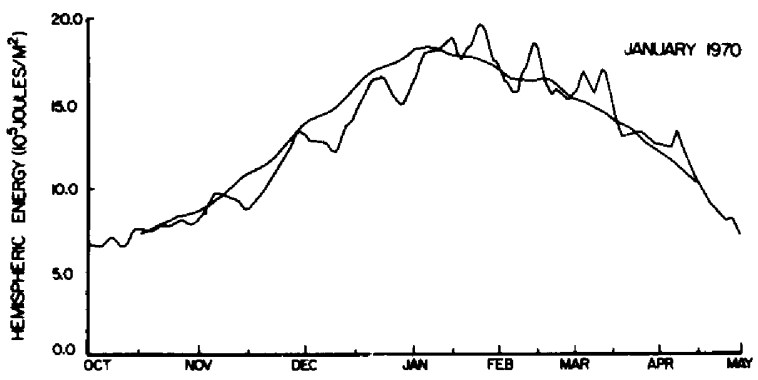

Fig. 30. Same as Fig. 28, except for zonal kinetic energy.

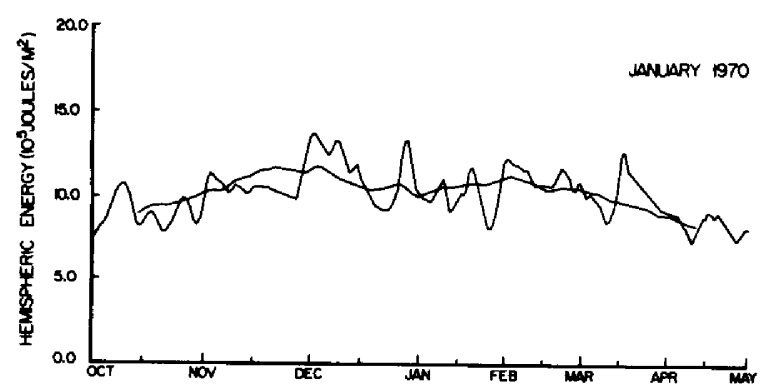

Fig. 31. Same as Fig. 28, except for eddy kinetic energy.

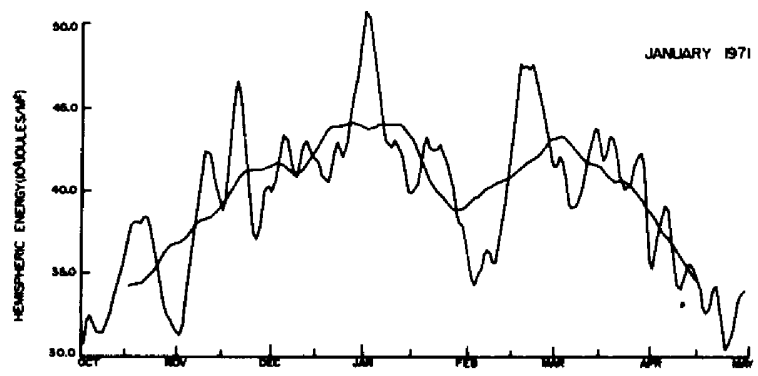

Fig. 32. Same as Fig. 24, except for period October 1970 through April 1971, zonal available potential energy.

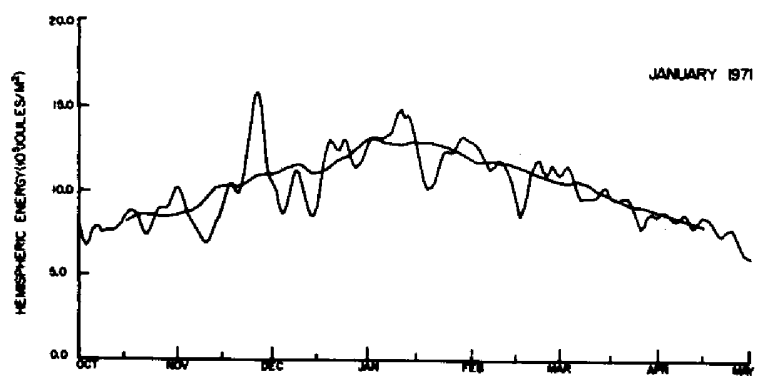

Fig. 33. Same as Fig. 32, except for eddy-available potential energy.

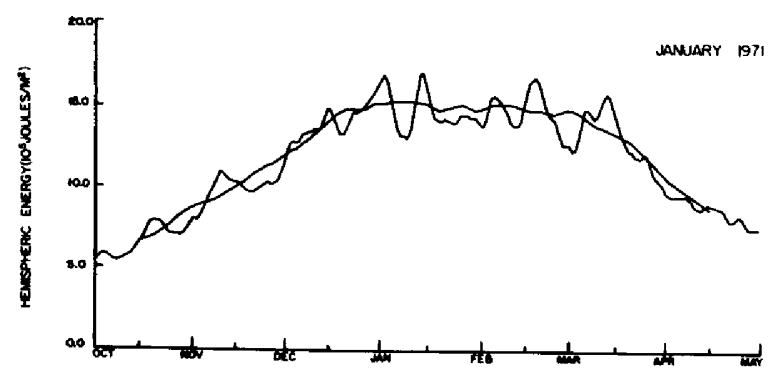

Fig. 34. Same as Fig. 32, except for zonal kinetic energy.

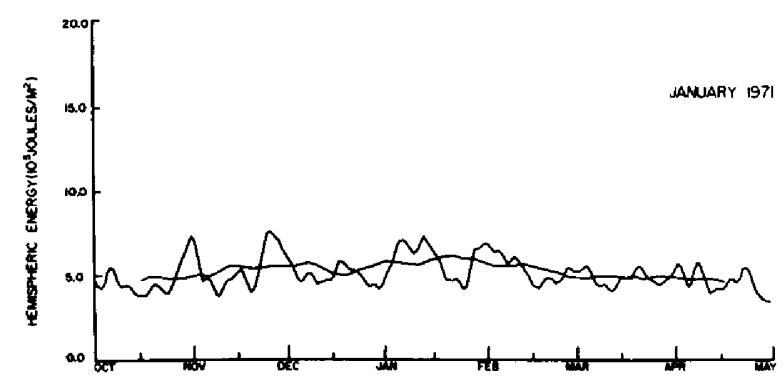

Fig. 35. Same as Fig. 32, except for eddy kinetic energy.

The most obvious characteristic of the data is the large "dip" in AZ in midwinter, unaccompanied by any major change in $\mathrm{AE}, \mathrm{KZ}, \mathrm{KE}{ }^{*}{ }^{*}$ Such a dip occurs in all three years analyzed so far with the relative minima appearing 27 December 1968, 7 March 1970, and $20 \mathrm{Janu}-$ ary 1971 . This phenomenon has been reported previously (Krueger et al, 1965), but very recently has been called into question (Peixoto and Oort, 1974). This conflict in opinions, as well as some possible explanations, are discussed later in some depth.

The second interesting feature of the data is the rather large short-term variation of individual hemispheric energy components. Particularly, KE and AE undergo changes of nearly $100 \%$ in just 8 or 10 days. Masked by its comparatively larger magnitude, $A Z$ often undergoes changes greater in magnitude than the eddy potential or kinetic energy in less than a week.

These comparatively large-amplitude fluctuations in the energy modes reveal significant phase relationships among the four parameters. This is evident in Fig. 36-38 which show typical three-day average deviations from 31-day averages. Of particular interest are the following correlations:

*The following notation has been adopted (Reiter, 1969a).

$A Z$ = Zonal Available Potential Energy

$A E=$ Eddy Available Potential Energy

$\mathrm{KZ}=$ Zonal Kinetic Energy

$\mathrm{KE}=$ Eddy Kinetic Energy 
1) $A Z$ and $K E$ appear nearly out of phase;

2) $\mathrm{AZ}$ and $\mathrm{AE}$ bear an even stronger out-of-phase relationship;

3) $\mathrm{KE}$ and $\mathrm{AE}$ are very close in phase to each other with KE leading AE by one or two days, contrary to expectations from conventional energy flow diagrams (see e.g., Reiter, 1969a for references and examples) which show $A E$ feeding KE.
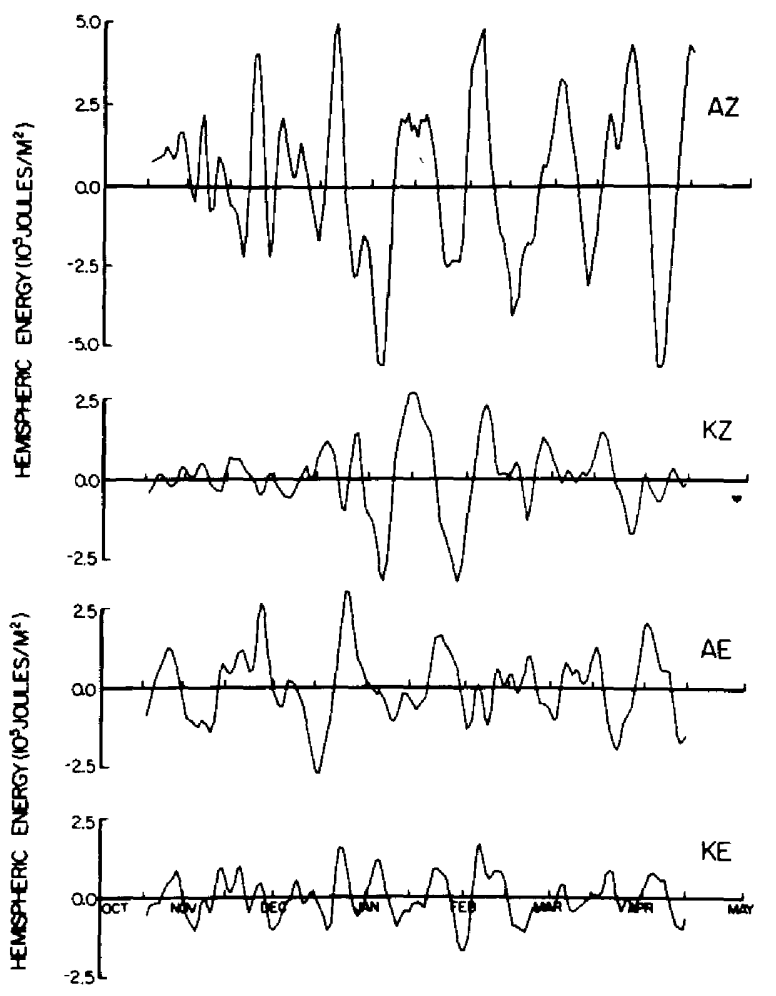

Fig. 36. Deviations of the 3-day average energy modes from their 31-day averages for the period october 1968 through April 1969.

Quasi-periodicities in the fluctuations of the four modes of energy, and correlations between them can be examined readily from auto- and cospectra of these energy parameters. An example is shown in Fig. 39. The points of each curve represents the contribution to the total variance by that particular harmonic frequency. The individual curves represent the average of the spectra of the three seasons October through April of 1968 to 1971 . These individual curves were constructed from appropriately smoothed Fourier transforms of the correlation functions.

The spectral power peak at about 24 days exceeds the $90 \%$ confidence level computed by the chi-square technique. The record length was too short to adequate ly define or establish the significance of the seasonal harmonic at about 90 days. In order to arrive at a significant peak in this frequency domain, one would have to include the summer months into the analysis. This might, however, alter the peak at 24 days, if during summer the characteristic energy cycles run on a somewhat different frequency by virtue of the reduced temperature gradient between equator and pole. The subharmonics of the 22-24 day cycle at 12 or 13 days and at seven or eight days, while present, do not seem highly significant. The spectrum for KZ was not extended below a period of 54 days because no peaks above the noise level were present. The implication is that $\mathrm{KZ}$ follows only the gross behavior of $\mathrm{AZ}$ and the total zonal kinetic energy is not too sensitive to tropospheric disturbances.
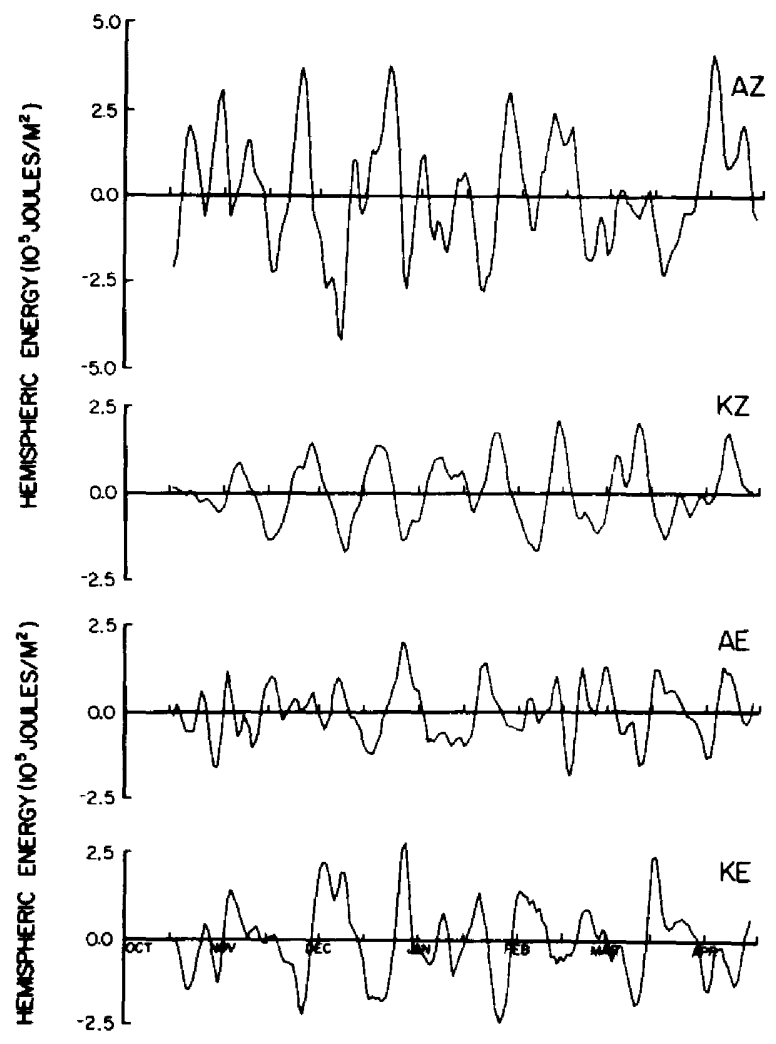

Fig. 37. Same as Fig. 36, except for time period October 1969 through April 1970.

The relationship between $A Z$ and $K E$ becomes quite evident under cross-spectrum analysis. In Fig. 40, the coherence, a measure of the correlated amplitudes of both signals, $A Z$ and $K E$, at a given frequency, and the spectral gain (cospectrum) which represents the amplitude of the cospectrum, are plotted. In mathematical terms the coherence is the ratio of the gain and the square root of the product of the individual autospectral power densities. At a given frequency if both signals ( $A Z$ and $K E$ ) are perfect sine waves, the coherence is equal to one; if both signals are uncorrelated white noise, the coherence should approach zero. The gain is the root-mean square of the real and imaginary parts of the cross spectrums of $A Z$ and $K E$. If the gain is significantly large at a given frequency, either $A Z$ or $K E$, or both $A Z$ and $K E$ have a strong harmonic at that frequency. If, in addition, the coherence is large (close to one), the harmonics of $\mathrm{AZ}$ and $\mathrm{KE}$ at that frequency have a strong linear dependence on each other. This also implies that while the two signals may differ in phase, this phase difference is approximately constant. Fig. 40 shows large values of gain at a frequency corresponding to a 25-day oscillation. This means that both $A Z$ and $K E$ vary significantly at this frequency. The coherence at the 25-day oscillation is also large (0.9) so that the variation of $A Z$ and $K E$ are strongly dependent on each other. The amplitude of the cospectrum (or gain) is almost as large as the seasonal amplitude. Also relatively strong are the subharmonics at 12 or 13 days. Fig. 38 shows that AZ leads KE by about 11 days, implying that $A Z$ and $K E$ are almost out 
of phase with respect to the 25-day vacillation. This is to be expected from the form of the conversion term $<A Z, A E>$ (see Reiter, 1969). The cospectra for the other two years show similar but slightly smaller peaks at about 25 days. We are presently investigating if this rather significant vacillation reflects itself in the "index cycle" of the northern hemisphere (see e.g., Quinet, 1974).

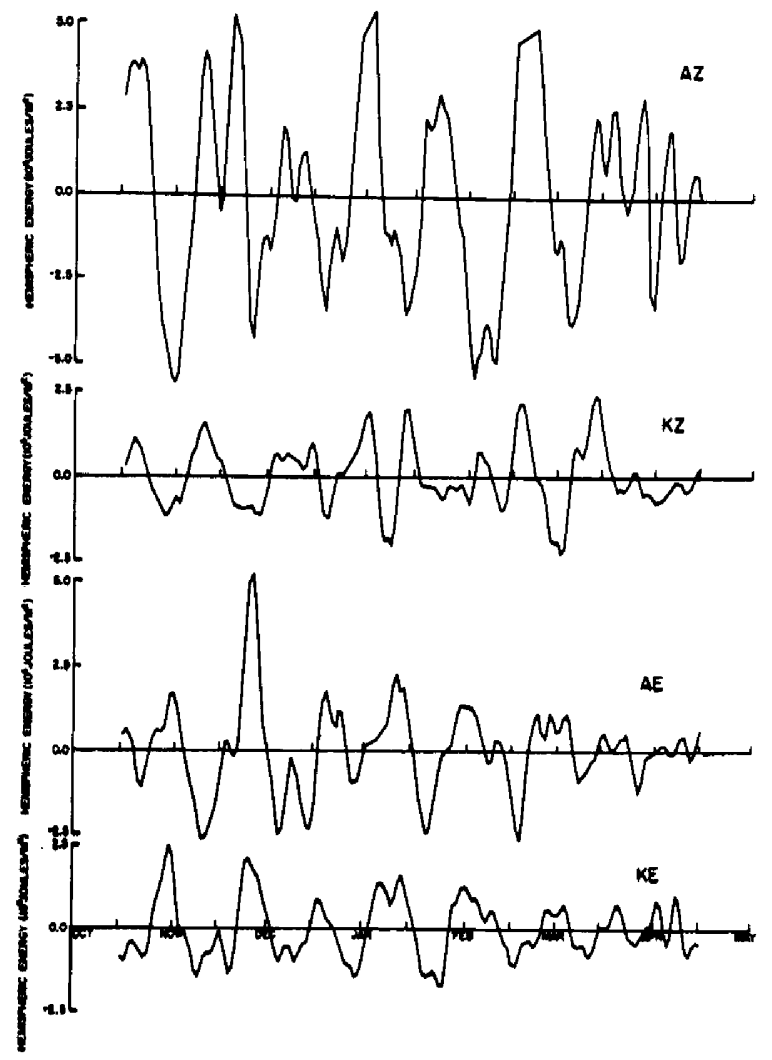

Fig. 38. Same as Fig. 36, except for time period October 1970 through April 1971.

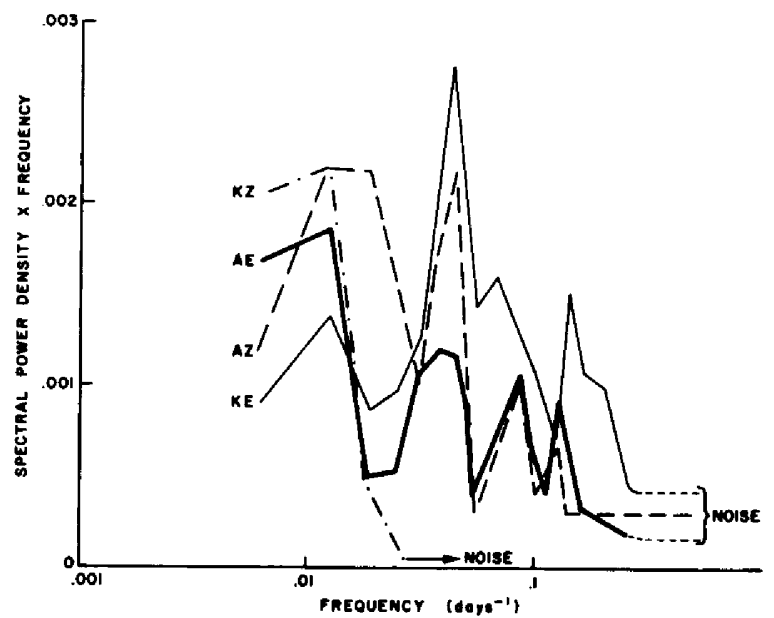

Fig. 39. Mean spectral power density of energy modes averaged over three winter seasons (October through April) from 1968 to 1971.

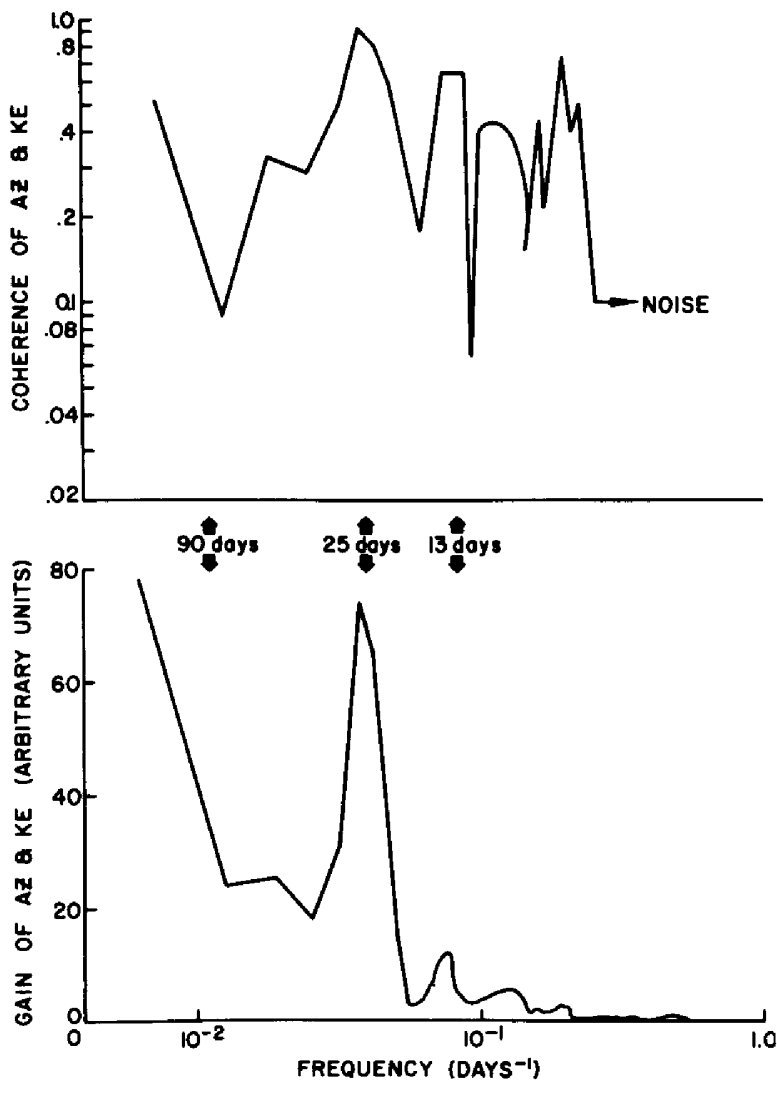

Fig. 40. Coherence and spectral gain of zonal available potential energy (AZ) and eddy kinetic energy (KE) for the winter season October 1968 to April of 1971 .

Because of this strong phase relationship between $A Z$ and $K E$, it seems evident that synoptic scale events (as measured by fluctuations in $\mathrm{KE}$ ) can be directly related to the zonally averaged available potential energy. This is also evident from the short-term variations of mean meridional temperature profiles (Fig. 41).

These profiles represent the average temperature of the layer 1000 to $100 \mathrm{mb}$. The curve for 10 February 1970 is representative for conditions prior to the decrease in $A Z$ (Fig. 28). As the zonal available potential energy decreases, the middle latitudes reveal a marked cooling trend and high latitudes exhibit a warming. We have not yet ascertained in detail to what extent the development of blocking patterns in the troposphere plays a role in this AZ "dip." A cursory examination of weather maps for the three seasons analyzed did not provide conclusive evidence for or against the significance of blocking.

A close relationship has been found between the magnitude of KE and the eddy-heat flux at some representative latitude (data will be supplied in a subsequent report).

Fig. 38 also reveals a relationship between $A E$ and KE. A close correlation between these two energy modes should be expected because both are caused by the same physical process: the growth of unstable baroclinic 
waves. The interesting phenomenon, however, is that $\mathrm{KE}$ leads AE. This is contrary to typical atmospheric energy-flow diagrams which show $A Z$ being converted to $A E$, which in turn is converted to KE. Thus at any time, the magnitude of $A E$ seems to be governed by the conversion $\angle A Z, A E>$ which, in turn, is strongly controlled by the magnitude of $\mathrm{KE}$ (Fig. 42). In a developing wave, $\mathrm{AE}$ seems to be converted very rapidly to $\mathrm{KE}$ while the frictional dissipation acts more slowly.

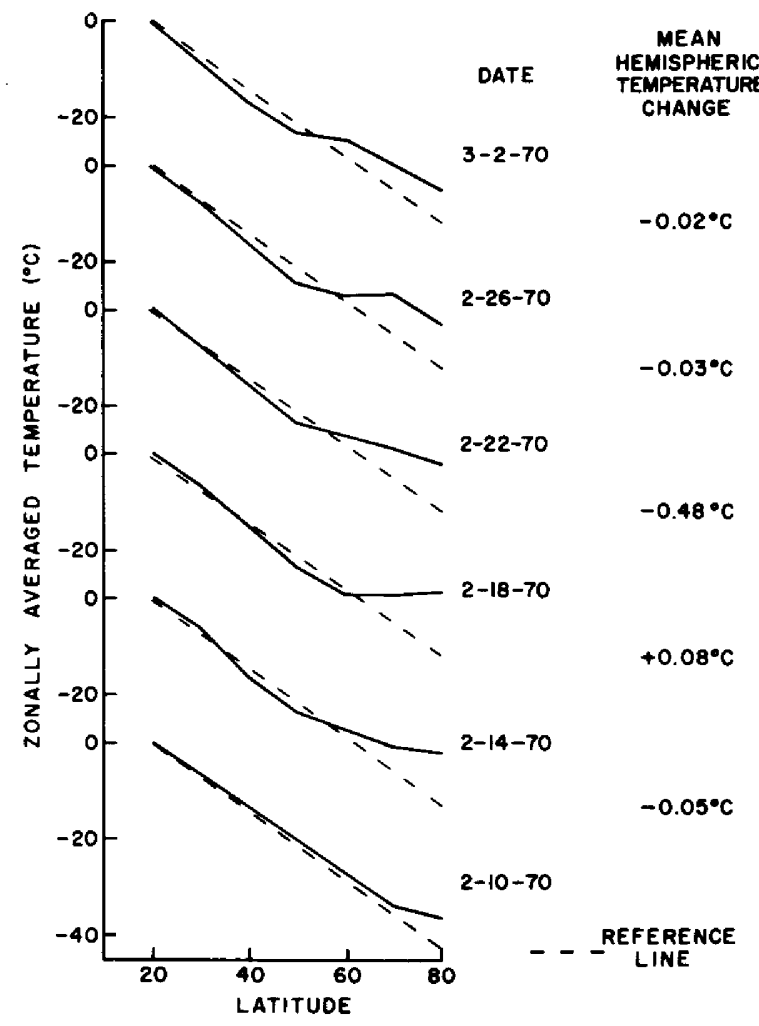

Fig. 41. Mean meridional temperature profile of the layer 1000 to $100 \mathrm{mb}$, and mean temperature change of spherical section north of $20^{\circ} \mathrm{N}$ for selected days surrounding a typical mid-winter decrease in $A Z$. The dashed line provides an arbitrary constant temperature profile.

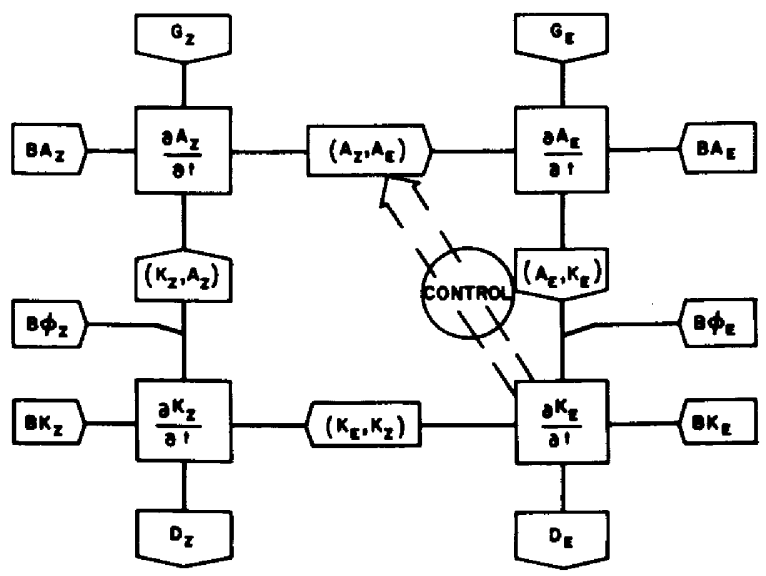

Fig. 42. Atmospheric energy transformation (see Reiter, 1969). There seems to be a feedback mechanism acting between $\mathrm{KE}$ and the transformation $\langle A Z, A E\rangle$.

\section{The Midwinter Decrease in Zonal Available Potential Energy}

As mentioned previously, a large drop $(10-20 \%)$ is noted in $A Z$ during mid to late winter. Such a drop has recently been questioned by Peixoto and Oort (1974). The present data reveal a drop in $A Z$ rather conclusive1y. Kruger et al. (1965) also find a significant midwinter dip in $A Z$. Besides the difference in time periods, the dissimilarities between the present data and those cited are:

1) We use 3- and 31-day running averages, whereas Peixoto and Oort use fixed monthly values averaged over five years.

2) We had to terminate our analyses at $20^{\circ} \mathrm{N}$ whereas Peixoto and Oort could extend their data base to $10^{\circ} \mathrm{S}$.

It is questionable whether cumulative monthly averages will depict with any clear definition an event whose periodicity is one and one-half months or less. As Peixoto and Oort readily admit, the difference between their results and those obtained by Kruger et al. (1965) may be explained in part by the boundary flux at $20^{\circ} \mathrm{N}$. There is some evidence that this is indeed the case. We can hypothesize that the total energy flux across $20^{\circ} \mathrm{N}$ is modulated by a latitudinal movement of the Hadley cell. If this were true one would anticipate similar changes in the flux at $10^{\circ} \mathrm{S}$, which should appear in Peixoto and Oort's data but are not evident there. If the large potential energy flux of the direct meridional Hadley cell decreases at latitude $20^{\circ} \mathrm{N}$, the eddy heat transport in midlatitudes will rapidly relax the $\mathrm{N}-\mathrm{S}$ temperature gradient.

Because the definition of a reference state of mean temperature as a function of height enters into the computation of available potential energy (Dutton and Johnson, 1973) $\overline{A Z}$ is particularly sensitive to smal1 movements of the Hadley cell. For example, small netmass fluxes northward across latitude $20^{\circ} \mathrm{N}$ will increase AZ simply by increasing the mean surface pressure. But even larger increases occur because of the relatively warmer air and the mean lower stability south of $20^{\circ} \mathrm{N}$. To estimate the magnitude of this effect, data for February from Oort and Rasmussen (1969) were used to calculate the change in $A Z$ north of $20^{\circ} \mathrm{N}$ that would result by including mean temperatures as a function of height in the latitude belt between equator and $20^{\circ} \mathrm{N}$, and thus arrive at a new reference state of potential energy in the northern hemisphere. It was determined that AZ of the northern hemisphere increases $4 \%$ due to the different mean temperature and $2.5 \%$ due to the different static stability that resulted from an inclusion of the latitude belt $0^{\circ}$ to $20^{\circ} \mathrm{N}$. In other words, the mass moving northward across $20^{\circ} \mathrm{N}$ will possess approximately $6.5 \%$ more $A Z$ simply by virtue of possessing a different reference state. Since changes in the mean meridional circulation are not detectable by the available NMC data, indirect evidence is presented to support the hypothesis of meridional flux across $20^{\circ} \mathrm{N}$.

Sample calculations were performed for the period 11 to 24 February 1970, in which $A Z$ decreased by 17\% and the total available energy $(A Z+A E+K Z+K E)$ decreased by $9.5 \times 10^{5}$ joules $/ \mathrm{m}^{2}$. If no energy flux across $20^{\circ} \mathrm{N}$ existed, this energy decrease would have to appear as dissipation into heat and, as a consequence, the total potential energy $\int \rho c_{p} T d$ (Volume) would have to increase. However, during this period, the total potential energy also decreased by two watts $/ \mathrm{m}^{2}$. We, thus, are faced with an "unexplained" energy decrease of nearly three watts $/ \mathrm{m}^{2}$. In addition to this, 0ort 
and Rasmussen estimate the steady-state frictional dissipation to be 2.3 watts $/ \mathrm{m}^{2}$. Therefore a decrease of somewhere between three and five watts $/ \mathrm{m}^{2}$ must be explained. Still ignoring the boundary flux across $20^{\circ} \mathrm{N}$, two possible explanations exist:

1) The steady-state radiation balance can be interrupted by large albedo changes or by increases of long-wave radiation; and ice.

2) Energy can be absorbed in evaporation of snow

We have ignored surface heating effects because they are deemed to act slower than the observed decreases in total atmospheric energy. Cursory analyses of satellite photographs do not indicate any marked changes of snow or cloud cover during the periods of energy decrease. (See U. S. Dept. of Commerce ESSA 9 data, 1971.) Therefore, it seems the "loss" in total energy cannot be accounted for by albedo changes. Furthermore, typical hemispheric values of the generation of $(\mathrm{AZ}+\mathrm{AE})$ are about six watts $/ \mathrm{m}^{2}$. The "unaccounted" energy decrease is almost as high, namely three to five watts $/ \mathrm{m}^{2}$. Albedo would have to vary by 50 to $100 \%$ if it were held responsible for this loss in energy due to the energy-generation terms (Reiter, 1969). Such variations, if indeed present, would be easily detected from satellite photographs.

Using areal extent of snow cover (Kukla and Kukla, 1974) an estimated evaporation of about one $\mathrm{cm}$ of water over this whole area would account for the observed energy deficit. If we assume, however, that evaporation takes place significantly only in the area over which the $0^{\circ} \mathrm{C}$ sea-level isotherm retracts toward the north, a water column of $20 \mathrm{~cm}$ would have to evaporate to make up for the energy loss.

Using Oort and Rasmussen's data, the following estimates for fluxes at $20^{\circ} \mathrm{N}$ in February can be made (units are in terms of watts per $\mathrm{m}^{2}$ of the total area north of $20^{\circ} \mathrm{N}$ ):

$\begin{array}{lcc}\text { Sensible heat } & : & 20 \mathrm{w} / \mathrm{m}^{2} \text { southward } \\ \text { Potential energy } & 46 \mathrm{w} / \mathrm{m}^{2} \text { northward } \\ \text { Latent heat } & : \frac{32 \mathrm{w} / \mathrm{m}^{2}}{6} \text { southward } \\ \text { Net flux } & : & 6 \mathrm{w} / \mathrm{m}^{2} \text { southward }\end{array}$

Thus it appears that net energy fluxes southward occur typically in late winter and possess magnitudes similar to those of the "unexplained" decreases in AZ.

If there is a substantial southward net flux of energy at $20^{\circ} \mathrm{N}$ we should expect a cooling in the area north of $20^{\circ} \mathrm{N}$. Fig. 41 shows such a net cooling between 18 and 22 February 1970 . From 10 February to 18 February 1970, the hemispheric temperature changes by about $+0.03^{\circ} \mathrm{C}$ but a fairly dramatic redistribution of hemispheric temperatures has occurred. The midlatitudes from $35^{\circ}-60^{\circ} \mathrm{N}$ have cooled while the pole has warmed markedly. Daily synoptic maps confirm this redistribution by showing a strong surge of tropical air flowing across the pole from a degenerating $\Omega$-block. From 18 February through 2 March the entire hemisphere cools. In February 1970 the large decrease in $A Z$ was accompanied by temperature drops of nearly $4^{\circ} \mathrm{C}$ in midlatitudes.

\section{Modeling of the Energy Cycle}

One of the primary reasons for investigating the spectral properties of the energy cycle is to gain sufficient insight into the interactions between the various energy components to allow some form of numerical simulation modeling. The modeling philosophy is based on two hypotheses:

(i) The atmosphere functions like a "dynamic system" in which the rapid increase of potential energy in late fall triggers an "overload-release mechanism" which drains the available potential energy. This mechanism is offered by unstable baroclinic waves. In the atmosphere it is highly over efficient in transporting heat poleward. It takes a certain time after such baroclinic energy releases before the hemispheric potential energy supply can build up again to a quantity sufficient to trigger the release mechanism.

(ii) This "dynamic system" can be empirically approximated by a system of forced-damped oscillators of the form:

$$
\frac{d N}{d t}=-\lambda N+a+\Sigma b_{i} \sin c_{i} t
$$

where $N$ is an energy mode; $a, b_{i}, c_{i}$ are empirical forcing terms. The first hypothesis is not new, having been suggested in slightly different forms by Kraus and Lorenz (1966) and Namias (1950). Its application to reproduce atmospheric general circulation variations should prove to be of interest.

The second hypothesis raises two questions:

(1) Can the energy cycle be modeled by a simple oscillator? By taking the output of the electrical analog of Kraus and Lorenz (1966), which looks very similar to a smoothed time series of $A Z$, it is possible to construct a differential equation similar to Eq. (1) which will approximate our observational data. Therefore, it seems quite probable that equations of the form Eq. (1) will be adequate for a simple model of the general circulation.

(2) Will the set of equations that tits our uuservational data be unique? The simple answer is no. As in any empirical model the assumption will be made that if external forcing to the atmosphere does not change greatly, two different sets of equations describing the same data set should produce approximately the same results.

This model is presently in its early design phase. It incorporates the following features:

(i) Four inhomogeneous, coupled, first-order, nonlinear equations describing the time-change of the four modes of energy.

(ii) Because of the analytic form of the conversion term from $A Z$ to $A E$, which depends on the meridional eddy velocity, it is hypothesized that this conversion will be controlled by the amplitude of the eddy kinetic energy. Thus, as suggested in Fig. 42, one or more positive feedback mechanisms will be incorporated into this model. 


\section{REFERENCES}

Bryson, R. A, 1974a: A Perspective on Climatic Change. Science, 184, 753-760.

, 1974b: The Lessons of C1imatic History. Paper presented at Conference on Weather and Climate Change, Food Production and Interstate Conflict Rockefeller Foundation, January 1974.

, 1974c: Paper presented at IFIAS Workshop, Bonn, Germany, May 1974.

Flohn, H., 1973: Globale Energiebilanz und Klimaschwankungen. Rheinisch-Westfälische Akademie der wissenschaften, $N$ 234, 75-117.

Kellogg, W. W. and S. H. Schneider, 1974: Climate Stabilization: For Better or Worse? Science, 186, 1163-1172.

Koch, L., 1945: The East Greenland Ice. Medd. Grönt, 130 , No. 3

Korff, H. C. and H. Flohn, 1969: Zusammenhang zwischen dem Temperaturgetälle Äquator-Pol und den planetarischen Luftdruckgürteln. Ann. Meeteorol. Neue Folge, 4, 163-164.

Koteswaram, P., 1958: The Easterly Jet Stream in the Tropics. Tellus, 10(1), 43-57.

Kraus, E. B. and Lorenz, 1966: Numerical Experiments With Large-Scale Seasonal Forcing J. Atmos. Sci., $23,3-12$.

Krueger, A. F., J. S. Winston and D. A. Haines, 1965: Computations of Atmospheric Energy and Its Transformation for the Northern Hemisphere for a Recent Five-Year Period. Mon. Wea. Rev., 93, 227-238.

Kukla, G. J. and H, J, Kukla, 1974: Increased Surface Albedo in the Northern Hemisphere. Science, 183 (4126), 709-714.

Landsberg, H. and J. M. Albert, 1975: Some Aspects of Global Climatic Fluctuations. To be published: Archiv Meteor. Geophys. Bioklim., Ser. B.

Maunder, W. J., 1970: The Value of the Weather. Methuen and Co., $388 \mathrm{pp}$.

Mbele-Mbong, S., 1974: Rainfall in West Central Africa. Colorado State Univ., Atmospheric Science Paper No. $222,126 \mathrm{pp}$.

Namias, J., 1950: The Index Cycle and Its Role in the General Circulation. J. of Met., 7, 130-139.

1969: Seasonal Interactions Between the North Pacific Ocean and the Atmosphere During the 1960's. Mon. Wea. Rev., 97 (3), 173-192.

Oort, A. H., 1974: Year-to-Year Variations in the Energy Balance of the Arctic Atmosphere. To be published: J. Geophysical Research.

and E. M. Rasmusson, 1971: Atmospheric Circulation Statistics. NOAA Prof. Pap. 5, 323 pp.

Palmén, E. and C. W. Newton, 1969: Atmospheric Circu1ation Systems, Their Structure and Physical Interpretation. Academic Press, New York, 603 pp.
Peixoto, J. P. and A. H. Oort, 1974: The Annual Distribution of Atmospheric Energy on a Planetary Scale. J. Geophys. Res., 79, 2149-2159.

Quinet, A., 1974: A Numerical Study of Vacillation. Advances in Geophysics, 17, 101-186.

Reiter, E. R., 1969a: Atmospheric Transport Processes, Part I: Energy Transfers and Transformations. Atomic Energy Comm., TID24868, 253 pp.

1969b: Tropospheric Circulation and Jet Streams. World Survey of Climatology, Vo1. 4, 85203, Elsevier Publishing Co., Amsterdam.

, 1975: Atmospheric Variability and Climatic Modelling. Proceedings of the Alaska Science Conference, Aug. 1973, to be published.

and B. C. Macdonald, 1973: Quasi-Biennial Variations in the Winter-Time Circulation of High Latitudes. Archiv Meteor. Geophys. Bioklim., Ser. A, $22(2-3)$, 145-167.

Rodewald, M., 1972: Einige hydroklimatische Besonderheiten des Jahrzehuts 1961-1970 im Nordat lantik und im Nordpolarmeer. Deutsche Hydrograph. Zeitschrift $25,97-117$.

Starr, V. P, and A. H. Oort, 1973: Five-Year Climatic Trend for the Northern Hemisphere. Nature, 242 , 310-313.

U. S. Dept of Commerce, 1971: Catalog of Meteorological Satellite Data-ESSA 9 Television Cloud Photography. Doc. No. 5.325, Silver Spring, Md.

Vinnichenko, N. K. and J. A. Dutton, 1969: Empirical Studies of Atmospheric Structure and Spectra in the Free Atmosphere. Radio Science, 4, 1115-1126.

Wiin-Nielsen, A., 1967. On the Annual Variation and Spectral Distribution of Atmospheric Energy. Te1lus, 19, 540-559. 
Authors: J.P. McGuirk, E.R. Reiter and A.M. Barbieri

ON THE VARIABILITY OF HEMISPHERIC SCALE ENERGY PARAMETERS

Colorado State University

Department of Atmospheric Science

Environmental Research Paper No..1, January :975. $15 p$

Nationa1 Science Foundation Grant No.GA-42215

U.S. Atomic Energy Commission Contract

No. $\operatorname{AT}(11-1)-1340$

Hemispheric scale energy parameters have been computed and their variability on an annual time scale and a scale of a few weeks is identified and discussed.

Based on data for 15 winter seasons, the annual variability of available potential energy is linked to fluctuations of elements of the general circulation, such as the jet streams. This link establishes a relationship between simply computed hemispheric scale parameters and regional weather conditions affecting man's economic we 11 being.

Authors: J.P. McGuirk, E.R. Reiter and A.M. Barbieri

ON THE VARIABILITY OF HEMISPHERIC SCALE ENERGY PARAMETERS

Colorado State University

Department of Atmospheric Science

Subject Headings: General Circulation Potential Energy

Kinetic Energy

Polar Front

Environmental Research Paper No. 1, January 1975. 15p.

National Science Foundation Grant No.GA-42215

U.S. Atomic Energy Commission Contract

No. AT $(11-1)-1340$

Hemispheric scale energy parameters have been computed and their variability on an annual time scale and a scale of a few weeks is identified and discussed.

Based on data for 15 winter seasons, the annual variability of available potential energy is linked to fluctuations of elements of the general circulation, such as the jet streams. This link establishes a relationship between simply computed hemispheric scale parameters and regional weather conditions affecting man's economic well being.
Authors: J.P. McGuirk, E.R. Reiter and A.M. Barbieri

551.513 .1

ON THE VARIABILITY OF HEMISPHERIC SCALE ENERGY PARAMETERS

Colorado State University

Department of Atmospheric Science General Circulation Potential Energy

Kinetic Energy

Polar Front

Environmental Research Paper No. 1, January 1975 . $15 p$.

National Science Foundation Grant No.GA-42215

U.S. Atomic Energy Commission Contract

No. $\operatorname{AT}(11-1)-1340$

Hemispheric scale energy parameters have been computed and their variability on an anual time scale and a scale of a few weeks is identified and discussed.

Based on data for 15 winter seasons, the annual variability of available potential energy is linked to fluctuations of elements of the general circulation, such as the jet streams. This link establishes a relationship between simply computed hemispheric scrle parameters and regional weather conditions affecting man's economic well being.

Authors: J.P. McGuirk, E.R. Reiter and A.M. Barbieri

ON THE VARIABILITY OF HEMISPHERIC SCALE ENERGY PARAMETERS

Colorado State University

Department of Atmospheric Science

Environmental Research Paper No. 1, January 1975. 15p.

National Science Foundation Grant No.GA-42215 U.S. Atomic Energy Commission Contract No. AT $(11-1)-1340$

Hemispheric scale energy parameters have been computed and their variability on an annual time scale and a scale of a few weeks is identified and discussed.

Based on data for 15 winter seasons, the annual variability of available potential energy is linked to fluctuations of elements of the general circulation, such as the jet streams. This link establishes a relationship between simply computed hemispheric scele parameters and regional weather conditions affecting man's economic well being.
Subject Headings General Circulation Potential Energy

Polar Front 
Daily statistics on three winter seasons of hemispheric energy modes have been analyzed with the ultimate goal of understanding and reproducing the behavior of the hemispheric energy cycle.

Two phenomena are discussed: (1) A strong 22-26 day cycle in the energy modes which may be linked to synoptic scale systems and the atmospheric index cycle; and (2) A large midwinter "dip" in zonal available potential energy which is tentatively linked to a possible movement of the Hadley cell. This "dip" is shown to have a profound effect on the meridional temperature gradient, particularly in midlatitudes.

Daily statistics on three winter seasons of hemispheric energy modes have been analyzed with the ultimate goal of understanding and reproducing the behavior of the hemispheric energy cycle.

Two phenomena are discussed: (1) A strong 22-26 day cycle in the energy modes which may be linked to synoptic scale systems and the atmospheric index cycle; and (2) A large midwinter "dip" in zonal available potential energy which is tentatively linked to a possible movement of the Hadley cell. This "dip" is shown to have a profound effect on the meridional temperature gradient particularly in midlatitudes.
Daily statistics on three winter seasons of hemispheric energy modes have been analyzed with the ultimate goal of understanding and reproducing the behavior of the hemispheric energy cycle. Two phenomena are discussed: (1) A strong 22-26 day cycle in the energy modes which may be linked to synoptic scale systems and the atmospheric index cycle; and (2) A large midwinter "dip" in zonal available potential energy which is tentatively linked to a possible movement of the Hadley cell. This "dip" is shown to have a profound effect on the meridional temperature gradient, particularly in midlatitudes.

Daily statistics on three winter seasons of hemispheric energy modes have been analyzed with the ultimate goal of understanding and reproducing the behavior of the hemispheric energy cycle. Two phenomena are discussed: (1) A strong 22-26 day cycle in the energy modes which may be linked to synoptic scale systems and the atmospheric index cycle; and (2) A large midwinter "dip" in zonal available potential energy which is tentatively linked to a possible movement of the Hadley cell. This "dip" is shown to have a profound effect on the meridional temperature gradient, particulariy in midlatitudes. 